\title{
Isolation and identification of intermediates of the oxidative bilirubin degradation
}

\author{
Marcel Ritter, ${ }^{\dagger}$ Raphael A. Seidel, ${ }^{\dagger, \S}$ Peter Bellstedt, ${ }^{\|}$Bernd Schneider, ${ }^{\#}$ \\ Michael Bauer, ${ }^{\S}$ Helmar Görls ${ }^{\|}$Georg Pohnert*, ${ }^{\dagger}$
}

${ }^{\dagger}$ Institute of Inorganic and Analytical Chemistry, Friedrich Schiller University, Lessingstrasse 8, D-07743 Jena, Germany,

"Institute of Inorganic and Analytical Chemistry, Friedrich Schiller University, Humboldtstrasse 8, D-07743 Jena, Germany,

${ }^{\S}$ Department of Anesthesiology and Intensive Care Medicine/Center for Sepsis Control and Care, Jena University Hospital, Erlanger Allee 101, D-07747 Jena, Germany,

\# Max Planck Institute for Chemical Ecology, Beutenberg Campus, Hans-Knöll-Str. 8, D-07745 Jena.

\section{Table of Contents}

I. General information S2

II. Oxidative degradation S3

III. Spectroscopic and spectrometric data $\quad$ S4

IV. X-ray diffraction measurements $\quad$ S17

V. Standard addition $\quad$ S18

References $\quad$ S18 


\section{General information}

$\underline{\text { Chemicals }}$

All solvents and compounds were purchased and used without further purification. HPLC gradient grade acetonitrile was obtained from VWR and water was purified with TKA microPure (Thermo Electron, Niederelbert, Germany). UHPLC gradient grade water and acetonitrile was purchased from Fisher Scientific (Loughborough, United Kingdom) and UHPLC formic acid was obtained from Biosolve B.V.

(Valkenswaard, Netherlands).

\section{$\underline{\text { Instrumentation }}$}

To remove solvents an evacuated centrifuge (Christ SpeedVac RVC 2-25) at $40{ }^{\circ} \mathrm{C}$ was used.

NMR data $\left({ }^{1} \mathrm{H},{ }^{13} \mathrm{C}\right.$-DEPT135, ${ }^{1} \mathrm{H},{ }^{13} \mathrm{C}$-HSQC $,{ }^{1} \mathrm{H},{ }^{13} \mathrm{C}$-HMBC $,{ }^{1} \mathrm{H},{ }^{1} \mathrm{H}$-ROESY $)$ was collected at room temperature with a $400 \mathrm{MHz}$ Bruker Avance I, a $600 \mathrm{MHz}$ Bruker Avance III and a $700 \mathrm{MHz}$ Bruker Avance III $\mathrm{HD}$ using the residual resonance of the solvent $\left[\mathrm{D}_{6}\right] \mathrm{DMSO}$ as internal standard for referencing. ATR-IR was measured with an IR-Affinity-1 from Shimadzu (Duisburg, Deutschland) and 20 scans per spectrum. Mass spectrometry and HPLC / UHPLC was carried out on the below-mentioned instruments.

\section{Preparative liquid chromatography}

For preparative separation a HPLC (Shimadzu LC-8A, Kyoto, Japan) with a HTEC C18-column (5 $\mu \mathrm{m}$, 250 x 16 mm, Macherey-Nagel, Düren, Germany) equipped with a SPD-10AV UV-VIS detector measuring at $280 \mathrm{~nm}$ was used. Solvent A contained $2 \%$ acetonitrile in water with $0.1 \%$ formic acid and solvent B $100 \%$ acetonitrile with $0.1 \%$ formic acid. The used gradient (flow rate of $6 \mathrm{~mL} / \mathrm{min}$ ) was as follows: $0 \mathrm{~min}$, $18 \%$ B; $38 \mathrm{~min}, 18 \% \mathrm{~B} ; 43 \mathrm{~min}, 25 \% \mathrm{~B} ; 50 \mathrm{~min}, 25 \% \mathrm{~B} ; 51 \mathrm{~min}, 100 \% \mathrm{~B} ; 61 \mathrm{~min}, 100 \% \mathrm{~B} ; 62 \mathrm{~min}, 18 \% \mathrm{~B}$; $72 \min , 18 \% \mathrm{~B}$. 


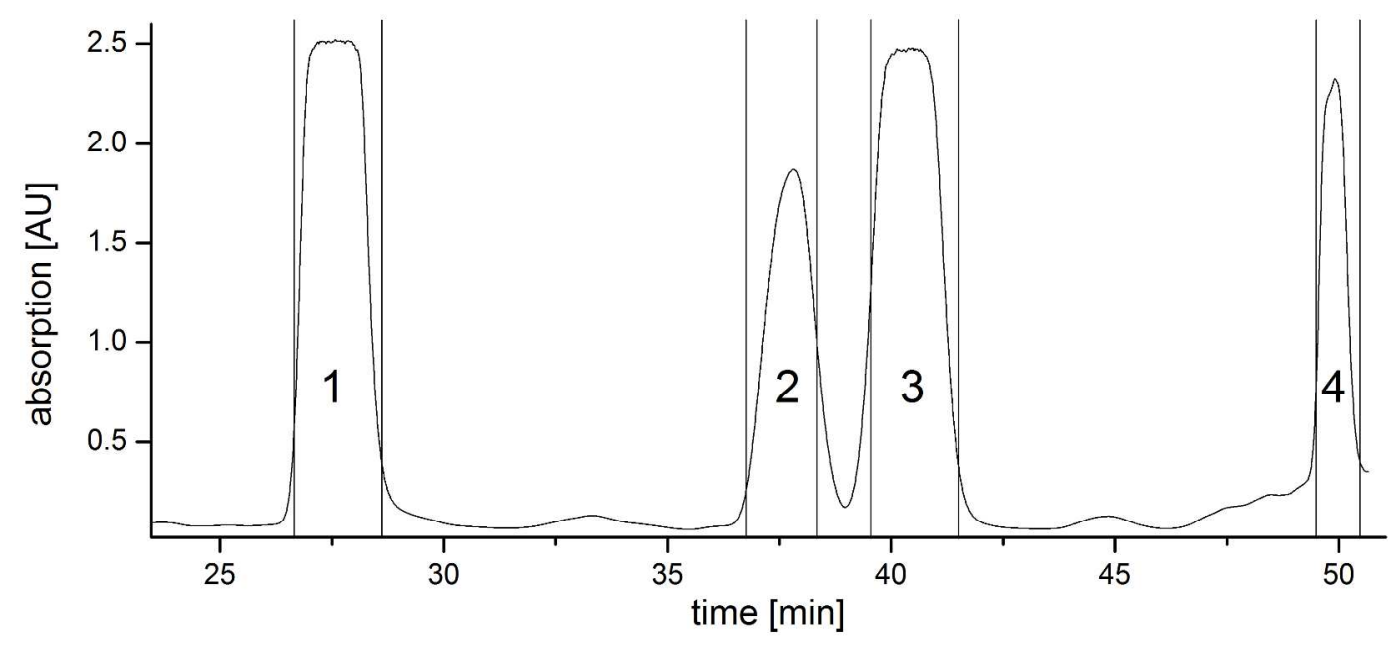

Figure S1. HPLC-UV/Vis chromatogram at $280 \mathrm{~nm}$ of the $20 \%$-ACN-fraction.

\section{$\underline{\text { LC-MS for PDP-analytics }}$}

For reaction monitoring a Dionex UltiMate 3000 UHPLC (Thermo Fisher Scientific, Leicestershire, United Kingdom), with a Kinetex C18 column $(1.7 \mu \mathrm{m}, 50 \times 2.1 \mathrm{~mm}$, Phenomenex, Aschaffenburg, Germany) coupled with a UV/Vis detector $(180-800 \mathrm{~nm})$ and with a Q-Exactive Plus Orbitrap mass spectrometer (Thermo Fisher Scientific, Leicestershire, United Kingdom) with electrospray ionization in positive ion mode was used. Solvents were used as described above with a flow rate of $0.4 \mathrm{~mL} / \mathrm{min}$ and the following solvent program: $0.0 \mathrm{~min}, 0 \% \mathrm{~B}$; $0.5 \mathrm{~min}, 0 \% \mathrm{~B} ; 1.0 \mathrm{~min}, 12 \% \mathrm{~B} ; 7.5 \mathrm{~min}, 17 \% \mathrm{~B} ; 8.0 \mathrm{~min}, 100 \% \mathrm{~B} ; 9.0 \mathrm{~min}, 100 \% \mathrm{~B}$; $9.1 \mathrm{~min}, 0 \% \mathrm{~B} ; 10.0 \mathrm{~min}, 0 \% \mathrm{~B}$. For quantification of PDPs the same solvent system was used with an Acquity UHPLC BEH C18 column $(1.7 \mu \mathrm{m}, 100 \times 2.1 \mathrm{~mm})$ and the following gradient was used: $0.0 \mathrm{~min}, 0 \%$ B; $0.5 \mathrm{~min}, 0 \% \mathrm{~B}$; $1.0 \mathrm{~min}, 18 \% \mathrm{~B}$; $8.0 \mathrm{~min}, 18 \% \mathrm{~B}$; $9.0 \mathrm{~min}, 100 \% \mathrm{~B} ; 10.9 \min , 100 \% \mathrm{~B} ; 11.0 \mathrm{~min}, 0 \% \mathrm{~B}$; $13.0 \mathrm{~min}, 0 \% \mathrm{~B}$ with external standards.

Preparation of biological samples

The bile and gallstone samples were prepared according to Seidel et al.. ${ }^{1}$

\section{Oxidative degradation}

\section{Bilirubin degradation procedure}

The oxidative degradation of bilirubin was carried out based on published protocols. ${ }^{2,3}$

Bilirubin ( $5 \mathrm{~g}, 8.6 \mathrm{mmol}$ ) was suspended in $2.5 \mathrm{~L} 5 \mathrm{M} \mathrm{NaOH}$ solution and stirred for $24 \mathrm{~h}$. The $\mathrm{pH}$ was adjusted to 7.5 with conc. $\mathrm{HCl}$ and $\mathrm{H}_{2} \mathrm{O}_{2}$ was slowly added (4 h) to a final concentration of $1 \%$ and stirred for 
$20 \mathrm{~h}$. After extraction with chloroform to isolate BOXes, the water phase was subjected to solid phase extraction (6 g-Oasis- hydrophilic lipophilic balanced cartridges; Waters, Manchester, United Kingdom). The cartridges were washed with water, prior to the elution of the degradation products were with $20 \%$ acetonitrile/water. Fractions were dried in an evacuated centrifuge and preparative HPLC-UV/vis was carried out to isolate the products. Due to the fast isomerization of the products it was necessary to freeze the fractions immediately with liquid nitrogen. After drying four different PDPs were obtained.

\section{$\underline{\text { Further degradation of PDPs }}$}

PDPs in equilibrium were dissolved in water $(50 \mu \mathrm{M}, 400 \mu \mathrm{L})$ and oxidized with $1 \%$ hydrogen peroxide under stirring for six days and measured daily with UHPLC-MS.

\section{Spectrometric and spectroscopic data}

$\underline{\text { MS measurements }}$

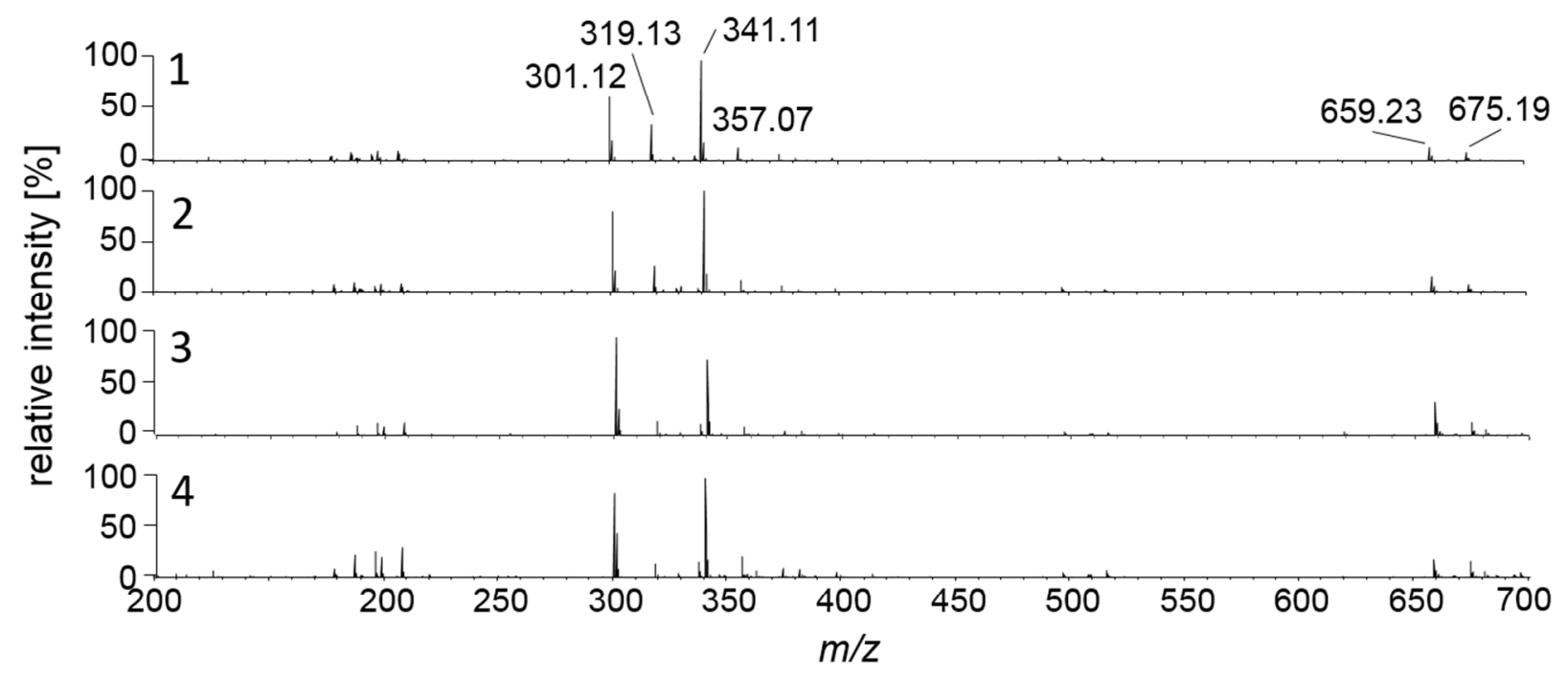

Figure S2. MS spectra of the four fractions with the following proposed fragments: $m / z=301.12$ as $[\mathrm{M}+\mathrm{H}-\mathrm{H} 2 \mathrm{O}]^{+}, m / z=319.13$ as $[\mathrm{M}+\mathrm{H}]^{+}, m / z=341.11$ as $[\mathrm{M}+\mathrm{Na}]^{+}, m / z=357.07$ as $[\mathrm{M}+\mathrm{K}]^{+}, m / z=659.23$ as $[2 \mathrm{M}+\mathrm{Na}]^{+}$and $m / z=675.19$ as $[2 \mathrm{M}+\mathrm{K}]^{+}$. 


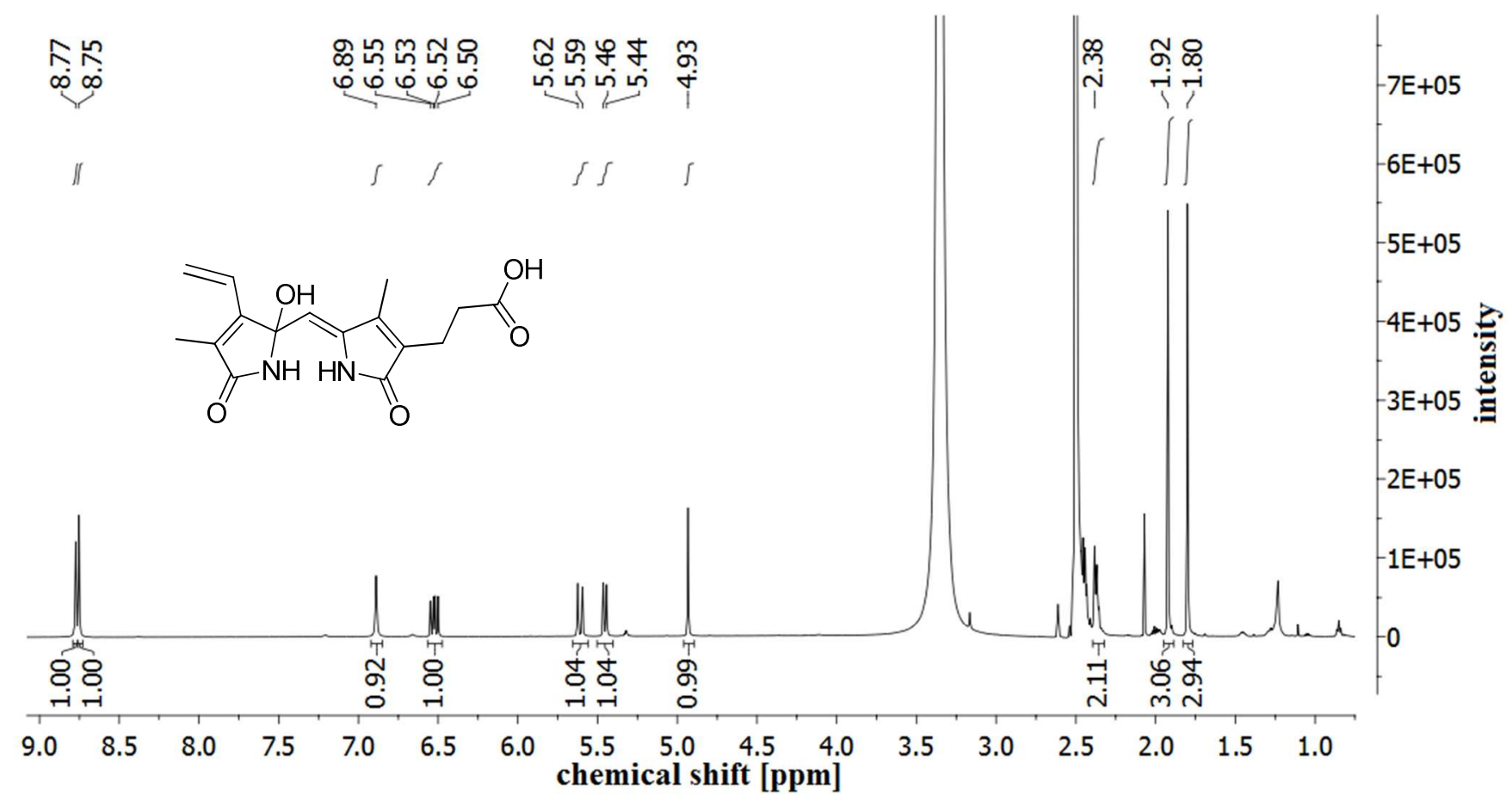

Figure S3: ${ }^{1} \mathrm{H}-\mathrm{NMR}$ spectrum $(600 \mathrm{MHz})$ of PDP A1 in $\left[\mathrm{D}_{6}\right] \mathrm{DMSO}$.

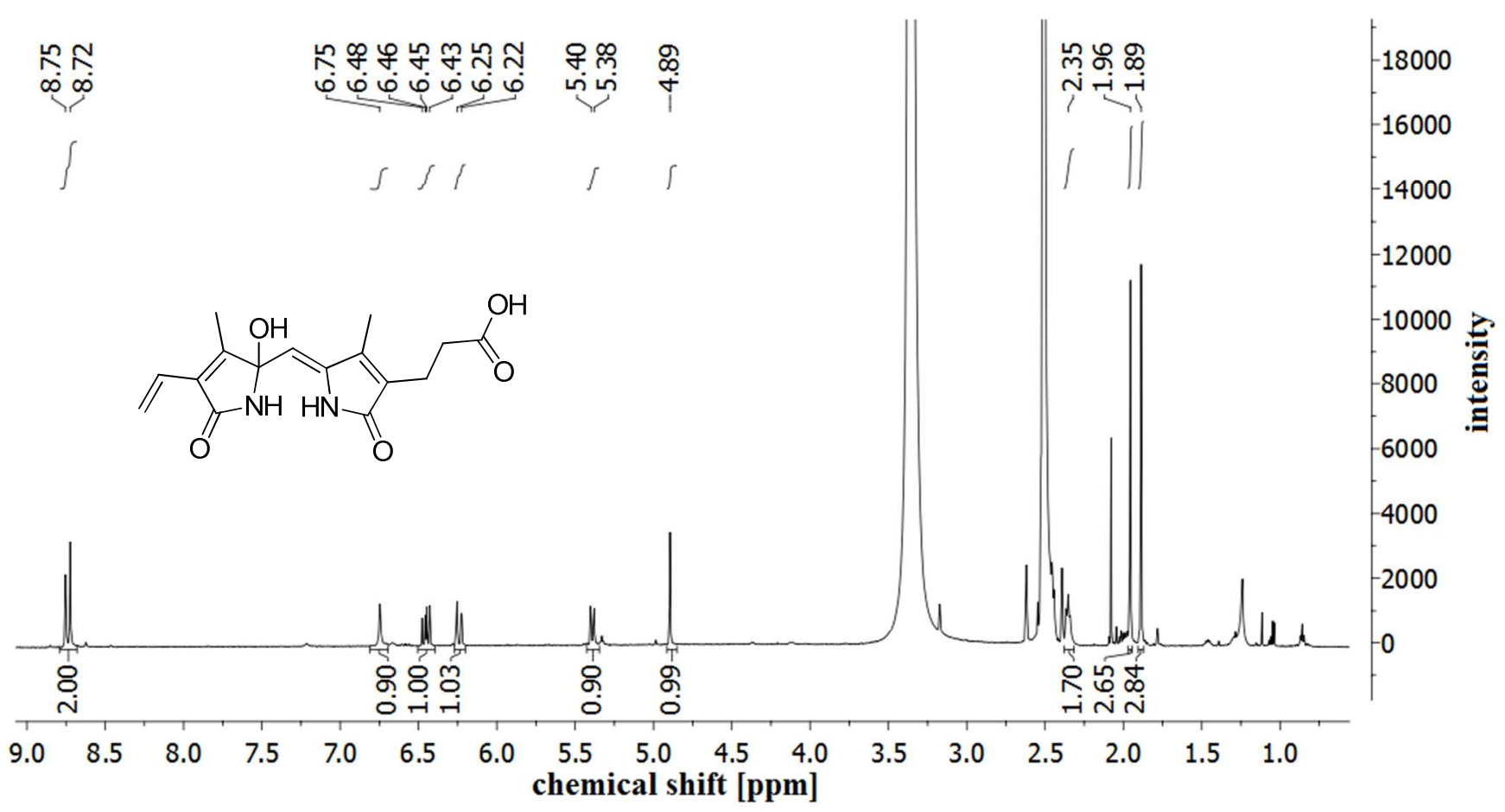

Figure S4: ${ }^{1} \mathrm{H}-\mathrm{NMR}$ spectrum $(600 \mathrm{MHz})$ of PDP B1 in $\left[\mathrm{D}_{6}\right] \mathrm{DMSO}$. 


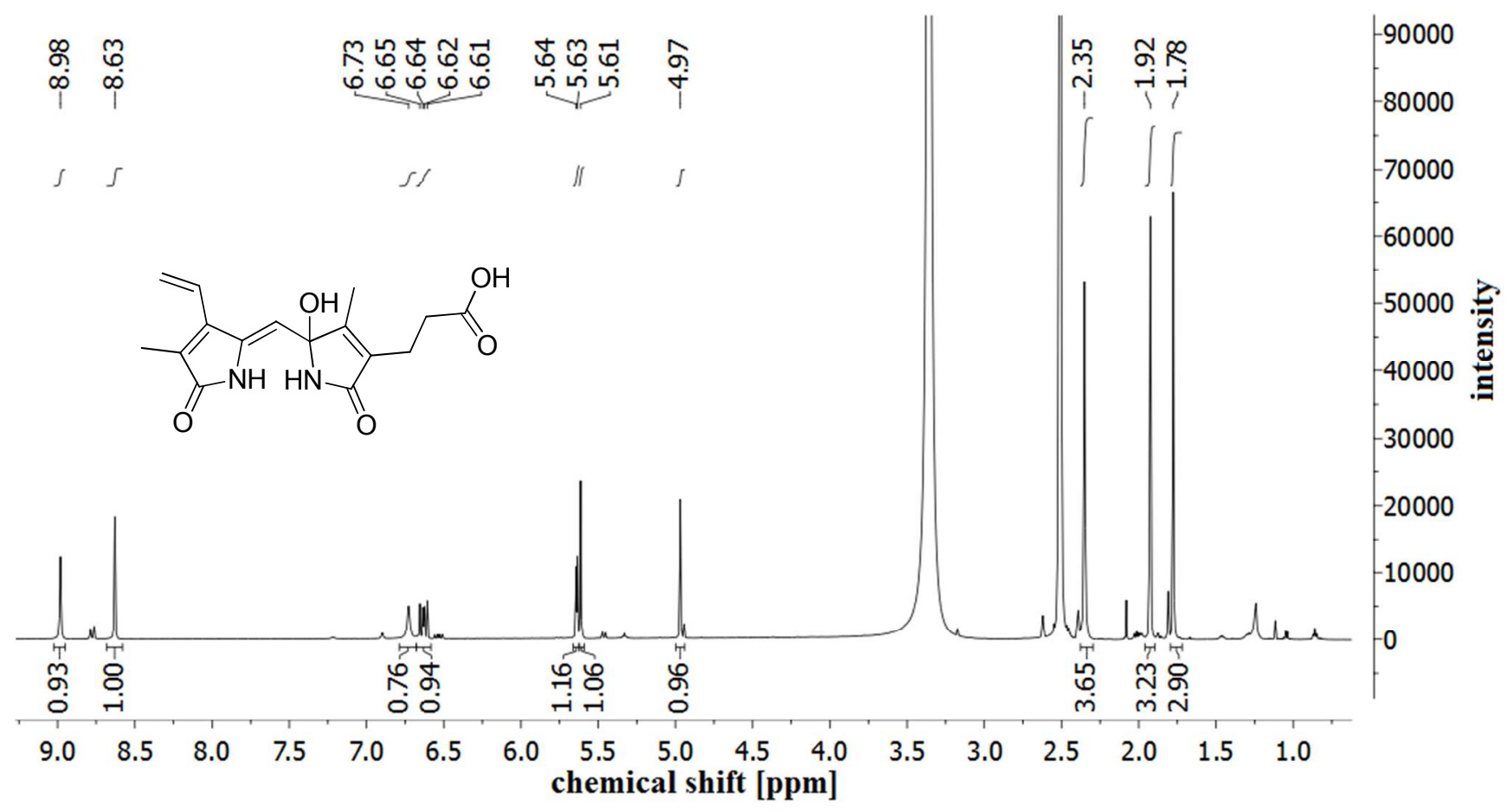

Figure S5: ${ }^{1} \mathrm{H}-\mathrm{NMR}$ spectrum $(600 \mathrm{MHz})$ of PDP A2 in $\left[\mathrm{D}_{6}\right] \mathrm{DMSO}$.

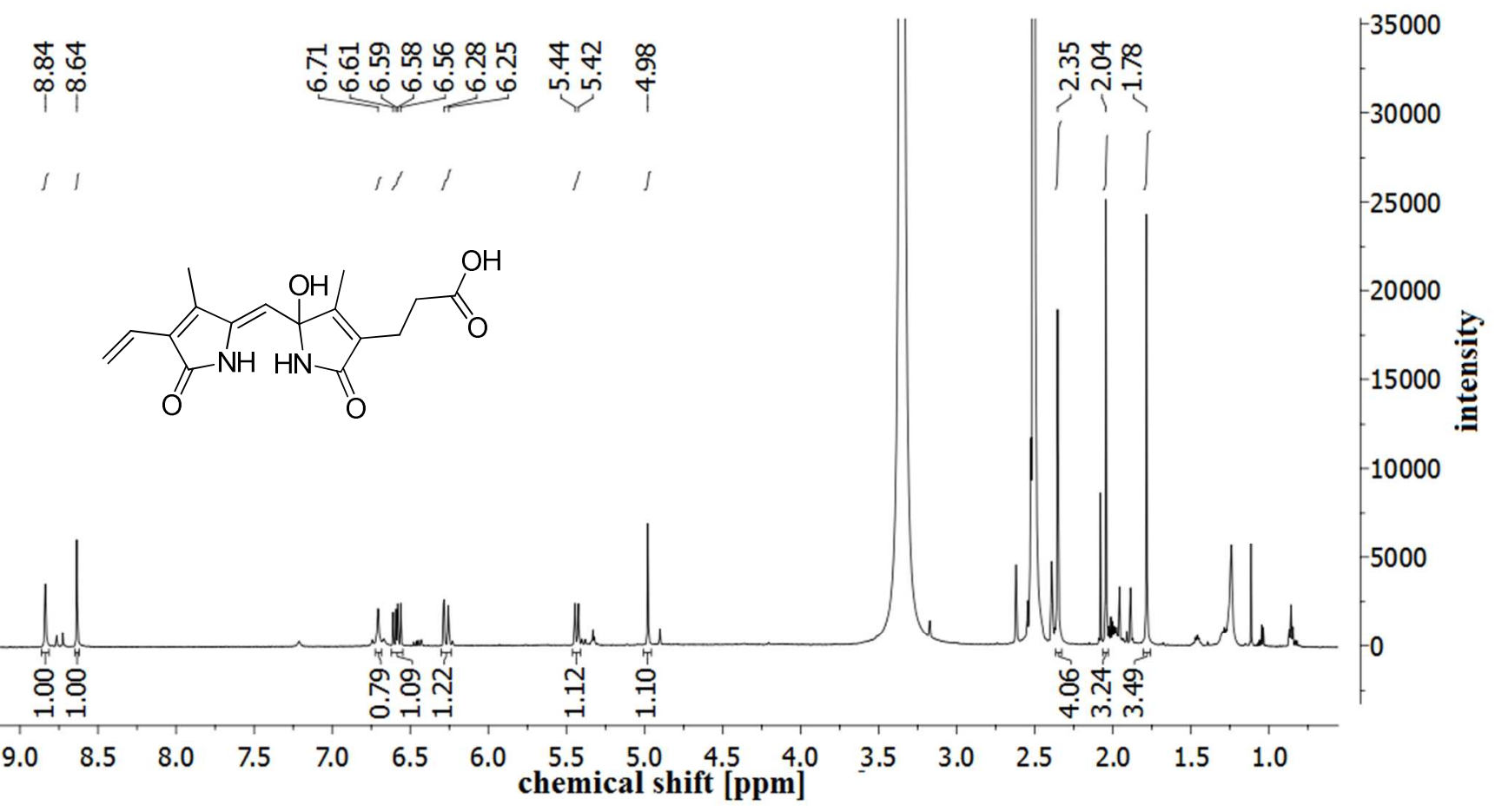

Figure S6: ${ }^{1} \mathrm{H}$ NMR spectrum $(600 \mathrm{MHz})$ of PDP B2 in $\left[\mathrm{D}_{6}\right] \mathrm{DMSO}$. 


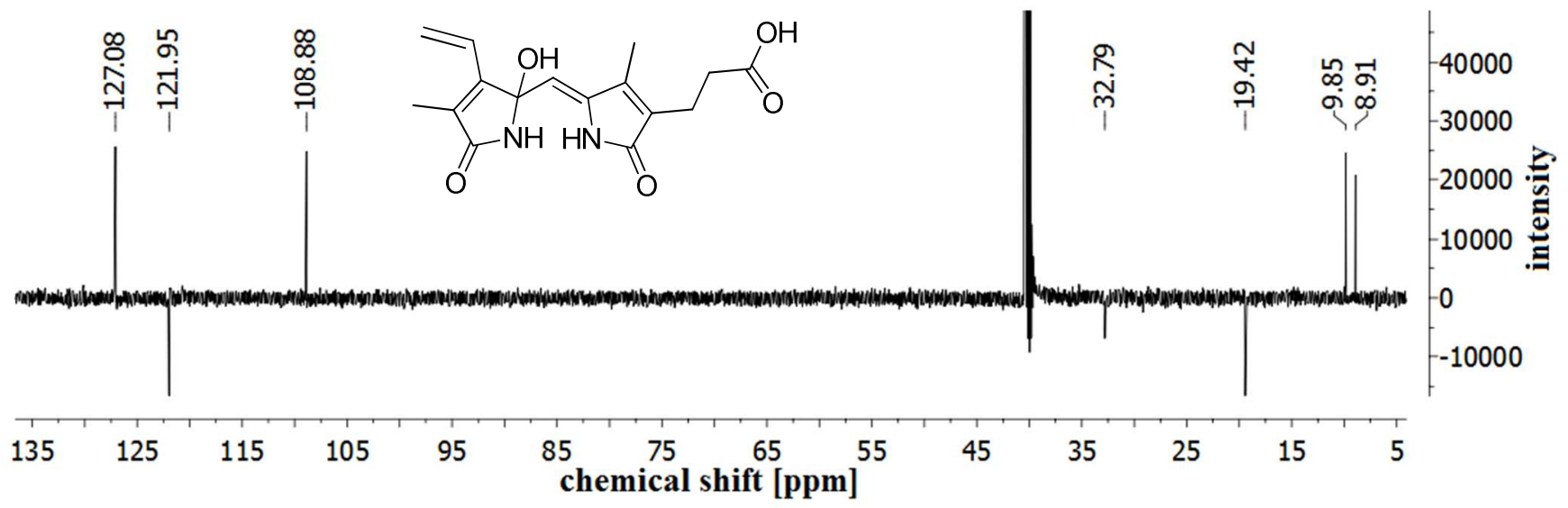

Figure S7: ${ }^{13} \mathrm{C}$-DEPT135 NMR-spectrum $(150 \mathrm{MHz})$ of PDP A1 in $\left[\mathrm{D}_{6}\right]$ DMSO.

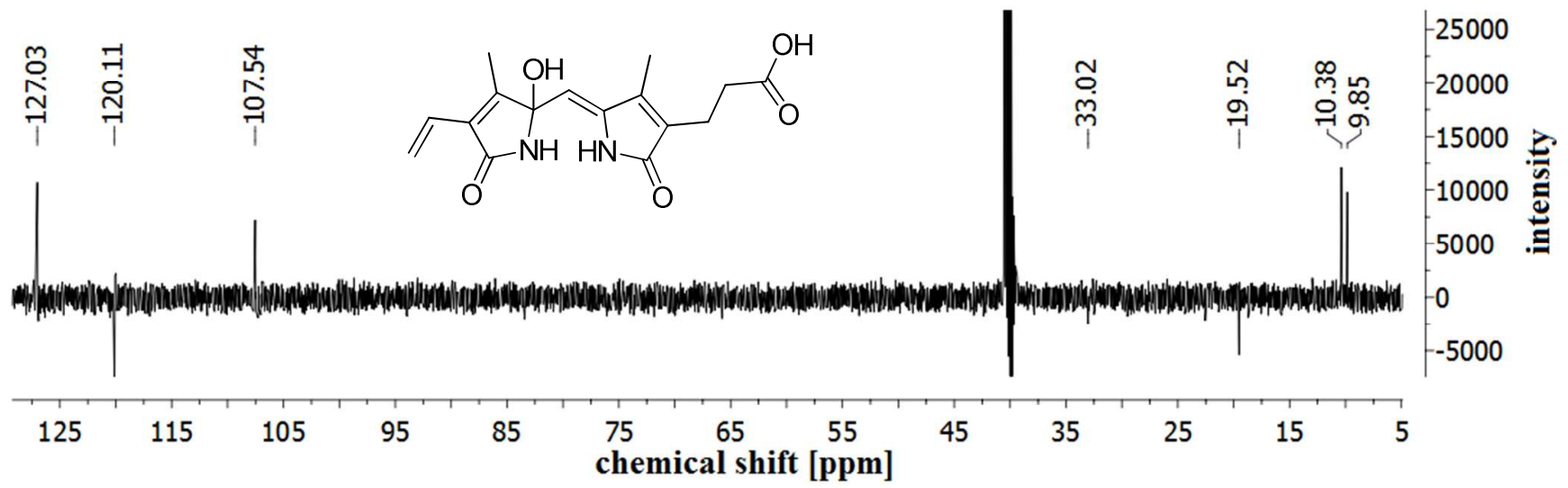

Figure S8: ${ }^{13} \mathrm{C}-\mathrm{DEPT} 135-\mathrm{NMR}$ spectrum $(150 \mathrm{MHz})$ of PDP B1 in [ $\left.\mathrm{D}_{6}\right]$ DMSO.

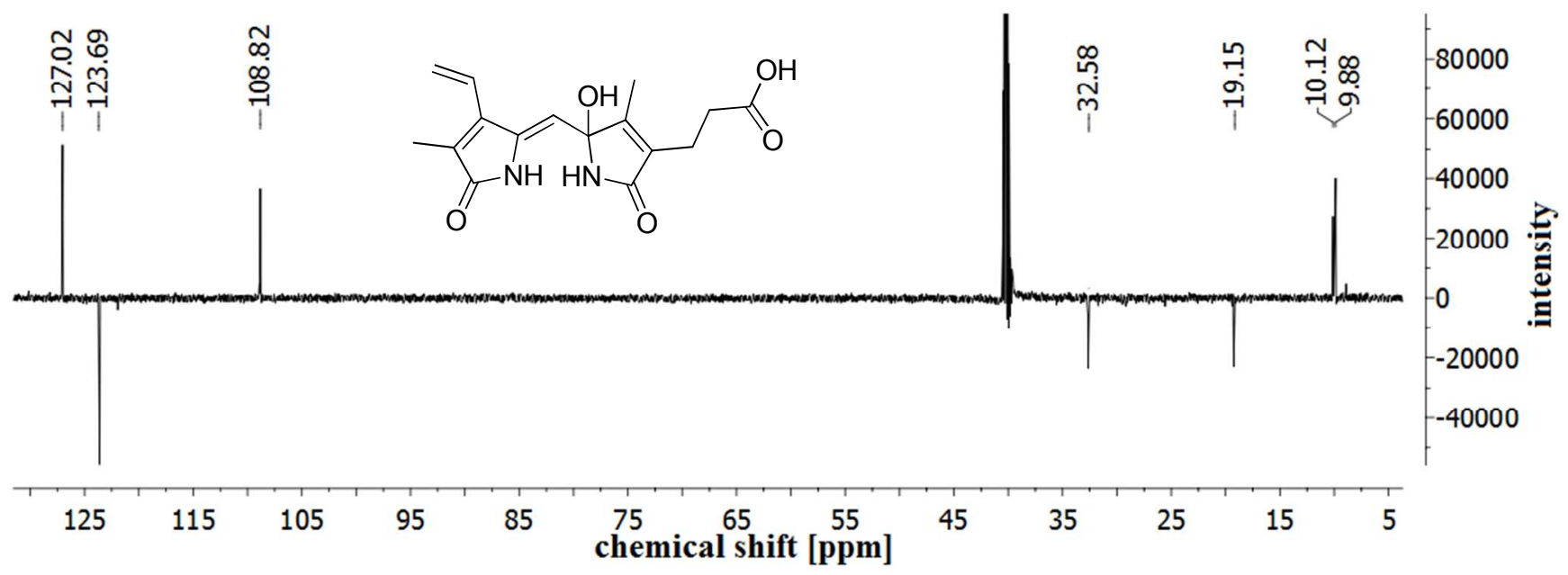

Figure S9: ${ }^{13} \mathrm{C}-\mathrm{DEPT} 135-\mathrm{NMR}$ spectrum $(150 \mathrm{MHz})$ of PDP A2 in [ $\left.\mathrm{D}_{6}\right] \mathrm{DMSO}$. 


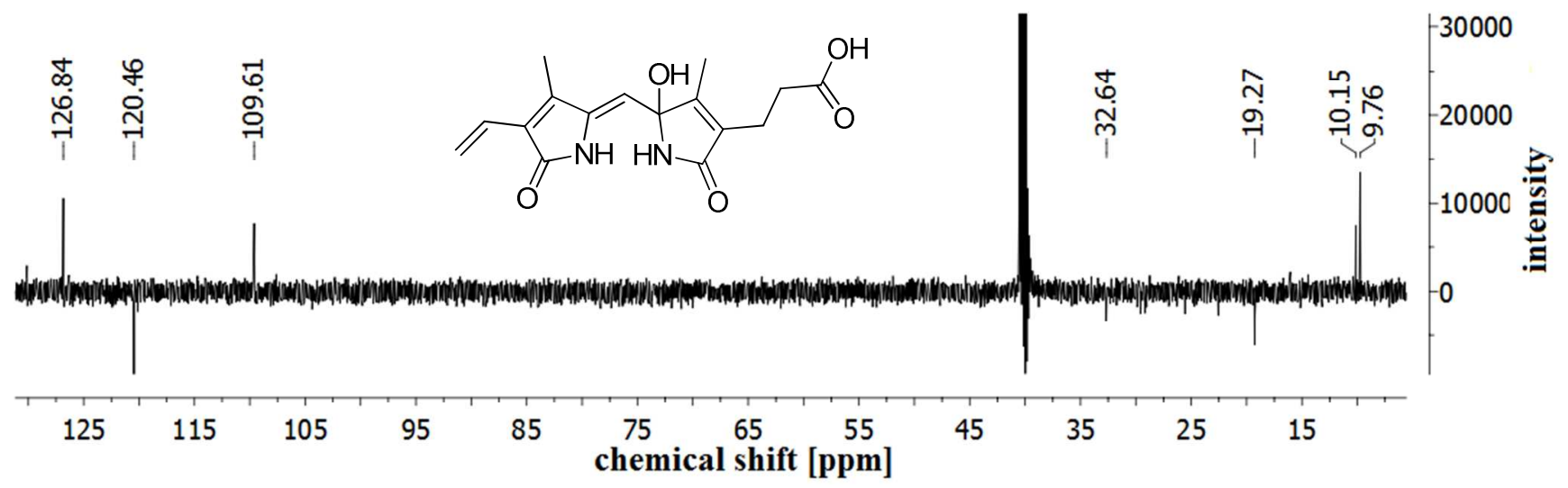

Figure S10: ${ }^{13} \mathrm{C}$-DEPT135-NMR spectrum $(150 \mathrm{MHz})$ of PDP B2 in $\left[\mathrm{D}_{6}\right] \mathrm{DMSO}$.

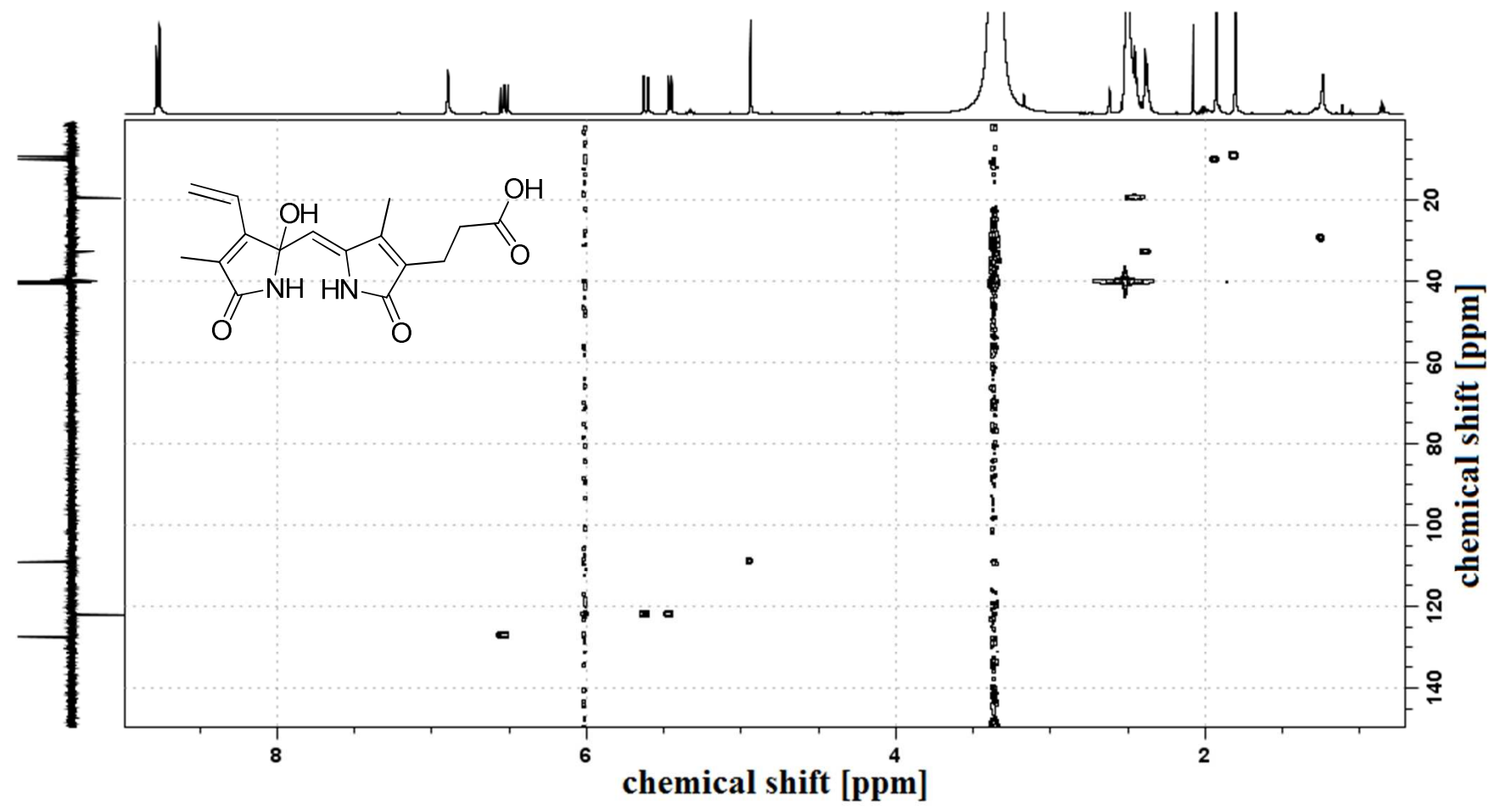

Figure S11: ${ }^{1} \mathrm{H},{ }^{13} \mathrm{C}-\mathrm{HSQC}-\mathrm{NMR}$ spectrum $(600 \mathrm{MHz})$ of PDP A1 in $\left[\mathrm{D}_{6}\right] \mathrm{DMSO}$. 


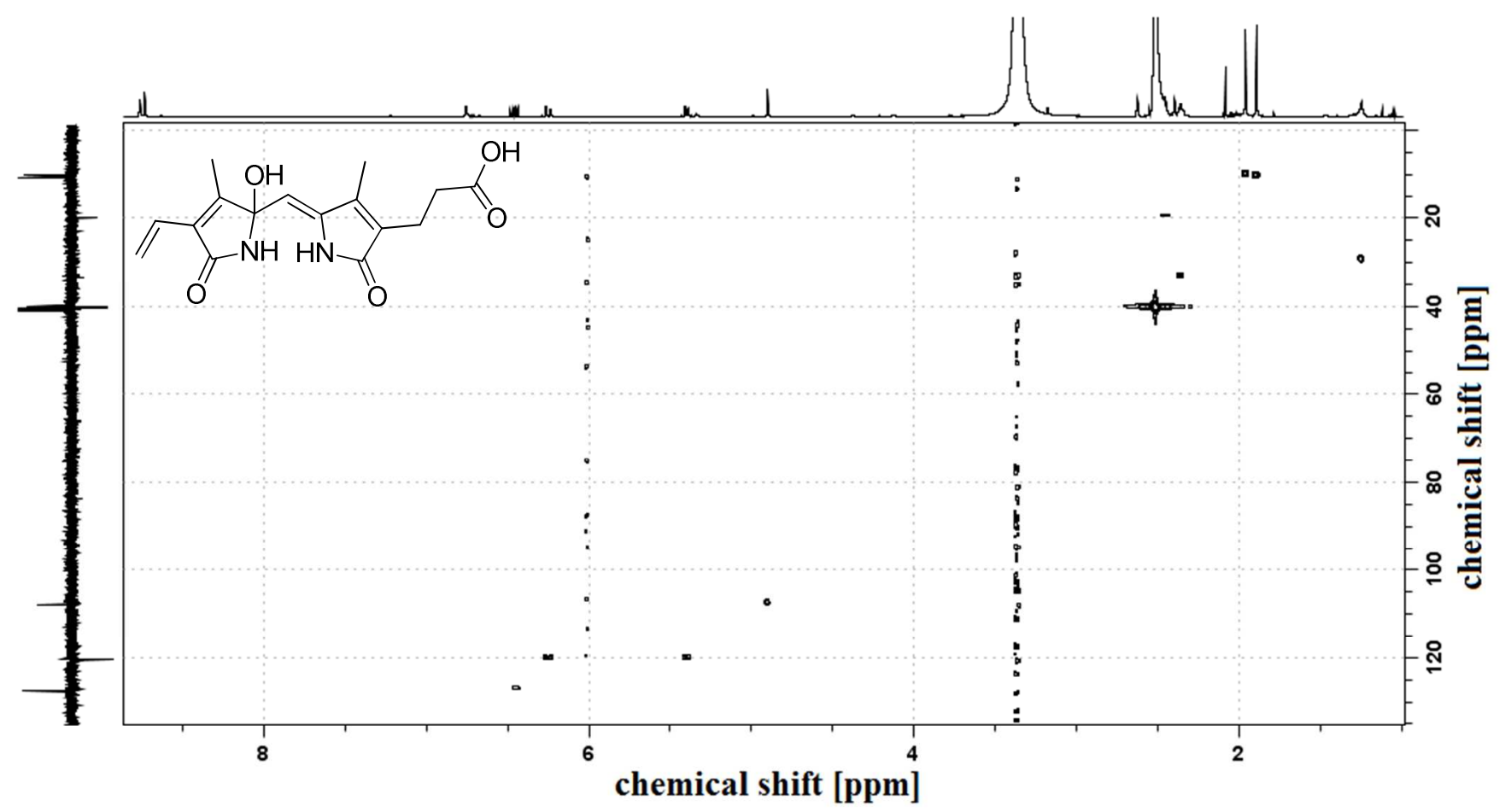

Figure S12: ${ }^{1} \mathrm{H},{ }^{13} \mathrm{C}-\mathrm{HSQC}-\mathrm{NMR}$ spectrum $(600 \mathrm{MHz})$ of PDP B1 in $\left[\mathrm{D}_{6}\right] \mathrm{DMSO}$.

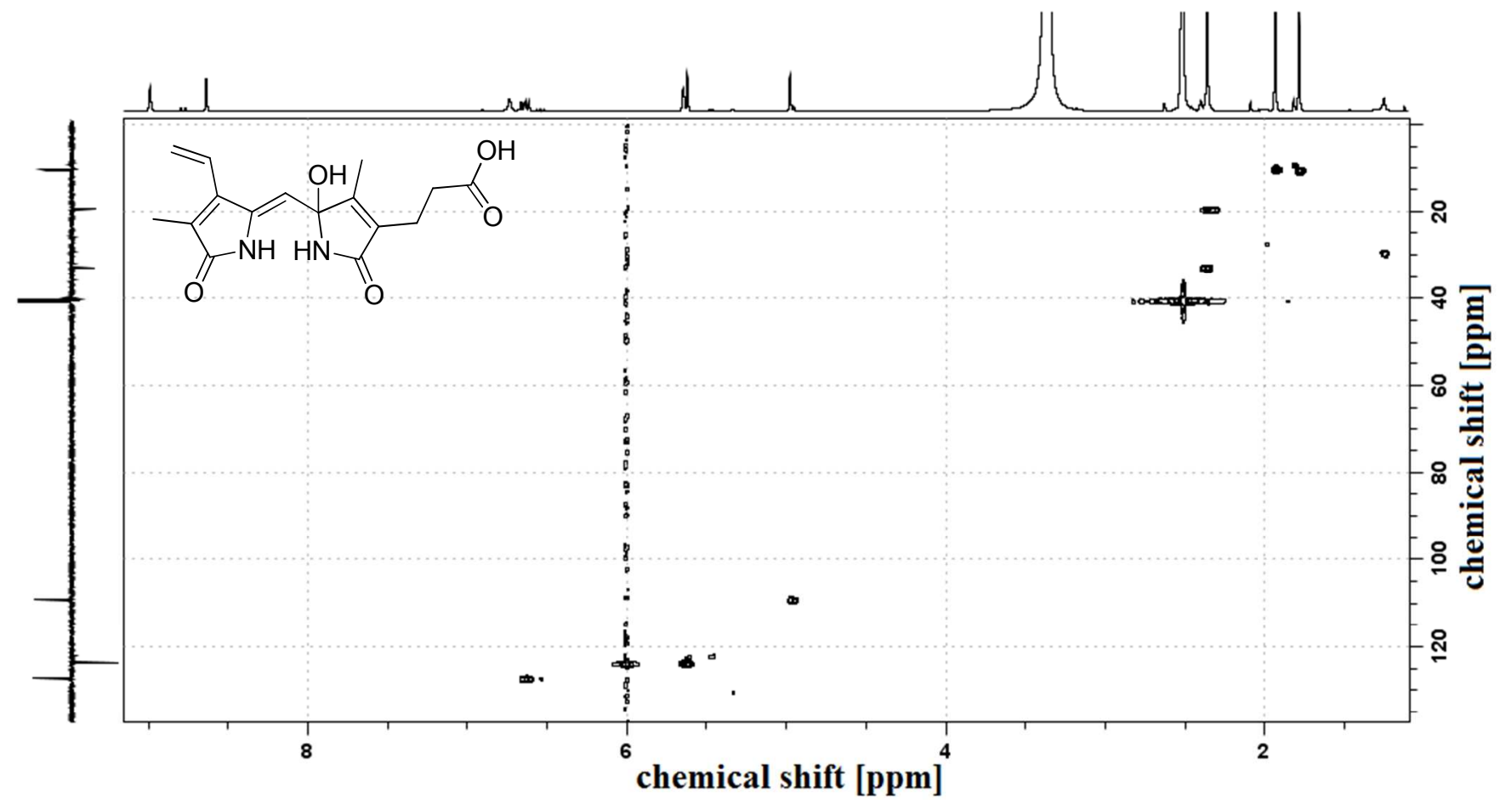

Figure $\mathrm{S} 13:{ }^{1} \mathrm{H},{ }^{13} \mathrm{C}-\mathrm{HSQC}-\mathrm{NMR}$ spectrum $(600 \mathrm{MHz})$ of PDP A2 in $\left[\mathrm{D}_{6}\right] \mathrm{DMSO}$. 


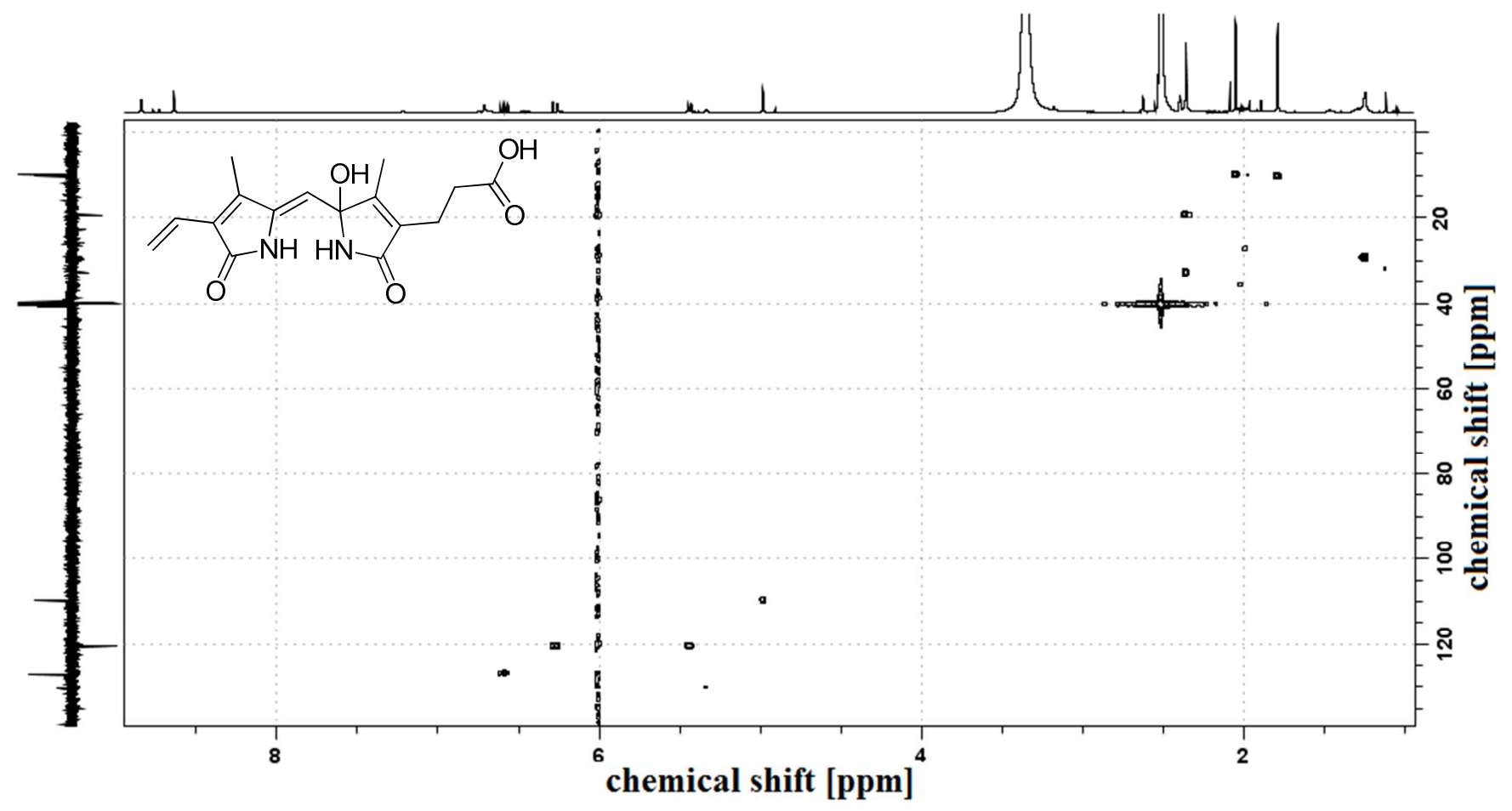

Figure S14: ${ }^{1} \mathrm{H},{ }^{13} \mathrm{C}-\mathrm{HSQC}-\mathrm{NMR}$ spectrum $(600 \mathrm{MHz})$ of PDP B2 in $\left[\mathrm{D}_{6}\right] \mathrm{DMSO}$.

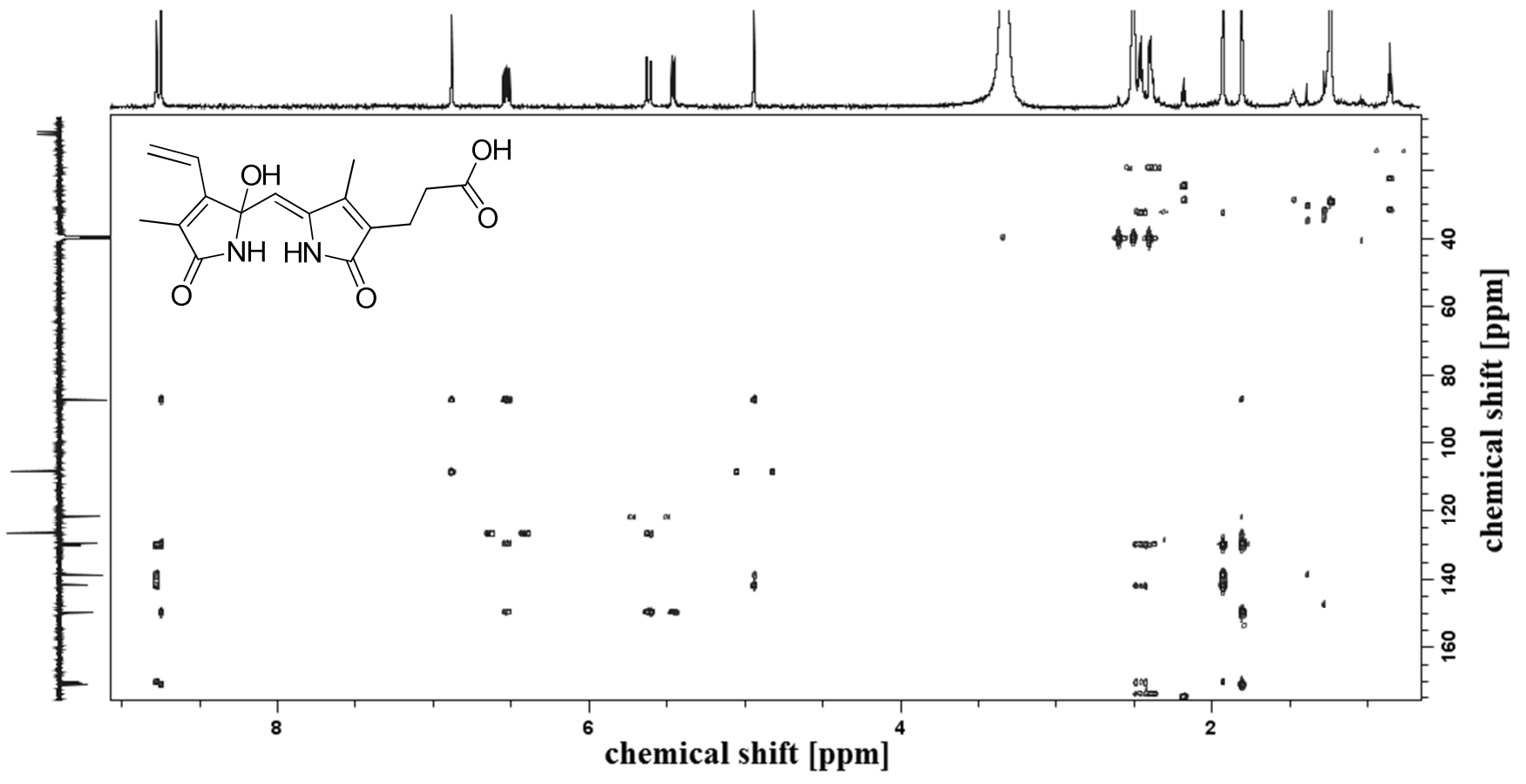

Figure S15: ${ }^{1} \mathrm{H},{ }^{13} \mathrm{C}-\mathrm{HMBC}-\mathrm{NMR}$ spectrum $(700 \mathrm{MHz})$ of PDP A1 in $\left[\mathrm{D}_{6}\right] \mathrm{DMSO}$. 


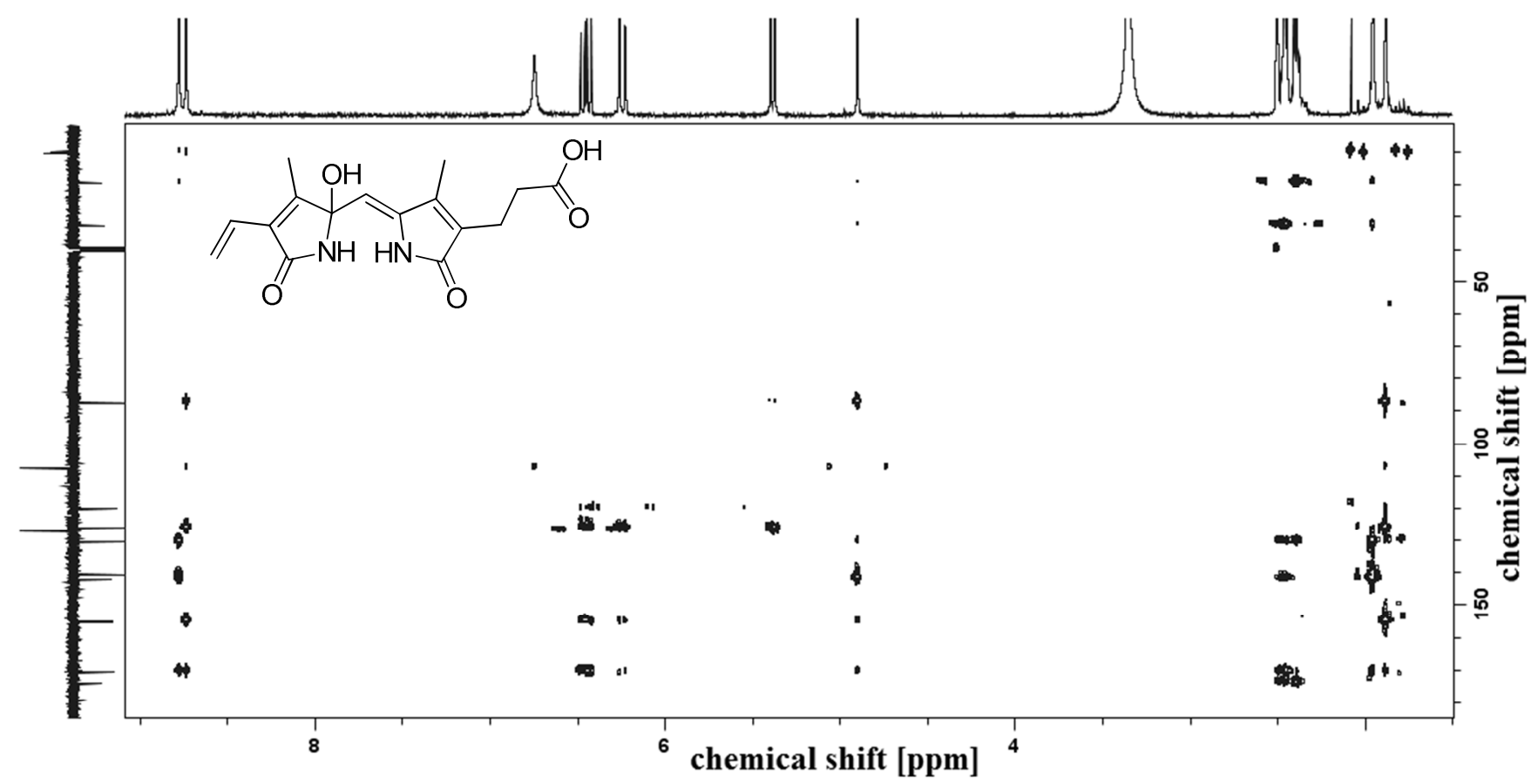

Figure S16: ${ }^{1} \mathrm{H},{ }^{13} \mathrm{C}-\mathrm{HMBC}-\mathrm{NMR}$ spectrum $(700 \mathrm{MHz})$ of PDP B1 in $\left[\mathrm{D}_{6}\right] \mathrm{DMSO}$.

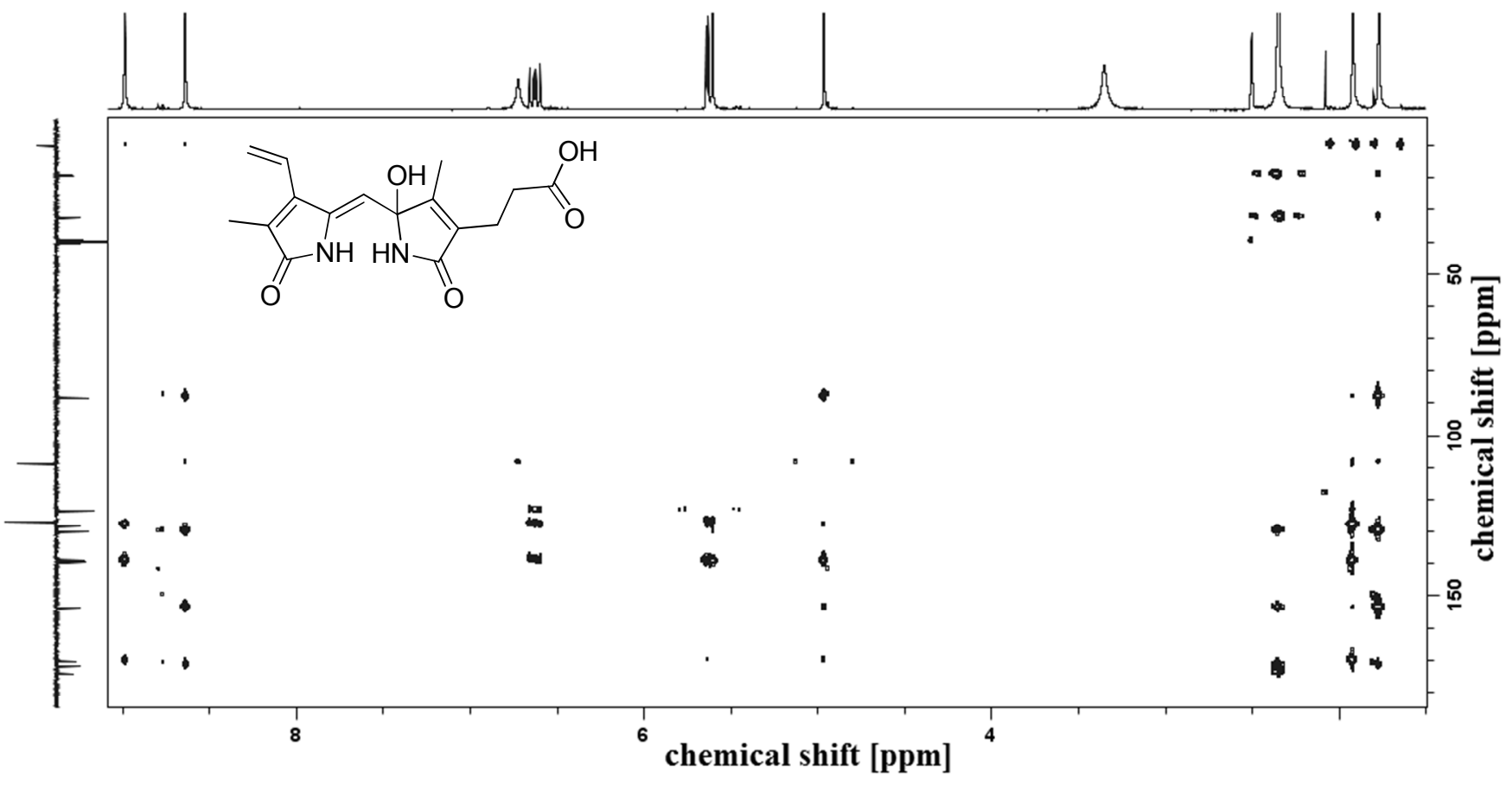

Figure S17: ${ }^{1} \mathrm{H},{ }^{13} \mathrm{C}-\mathrm{HMBC}-\mathrm{NMR}$ spectrum $(700 \mathrm{MHz})$ of PDP A2 in $\left[\mathrm{D}_{6}\right] \mathrm{DMSO}$. 


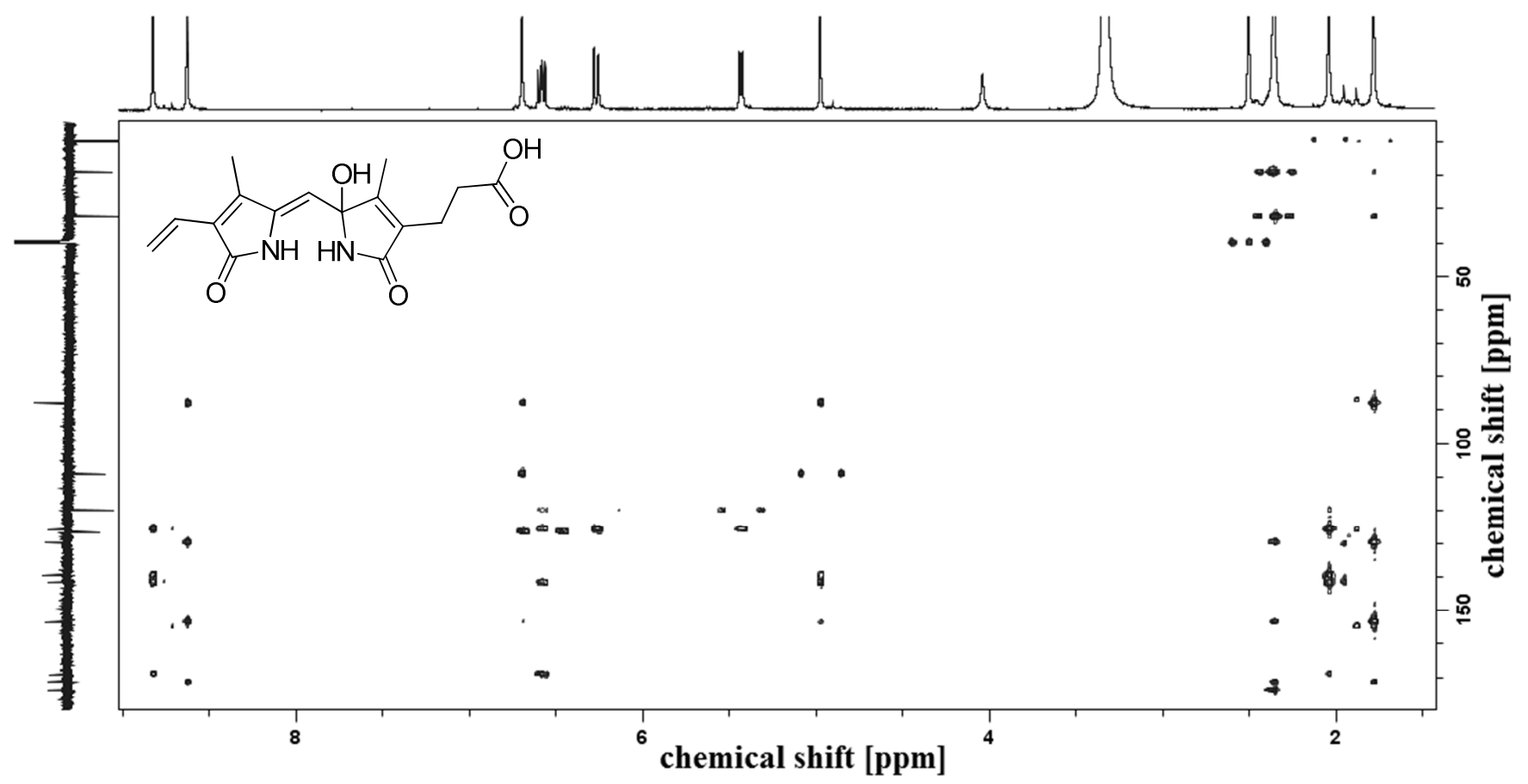

Figure S18: ${ }^{1} \mathrm{H},{ }^{13} \mathrm{C}-\mathrm{HMBC}-\mathrm{NMR}$ spectrum $(700 \mathrm{MHz})$ of PDP B2 in $\left[\mathrm{D}_{6}\right] \mathrm{DMSO}$.

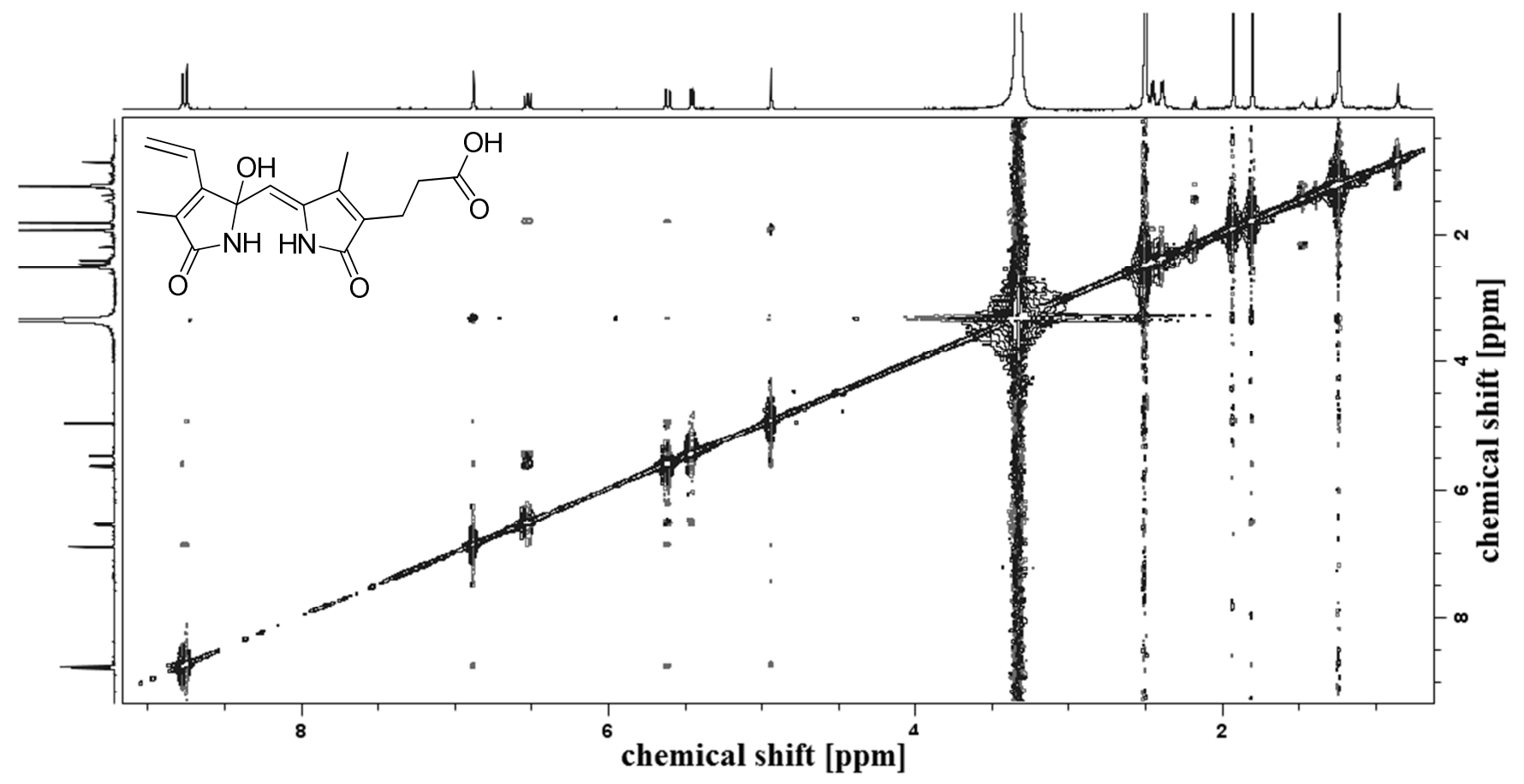

Figure S19: ${ }^{1} \mathrm{H},{ }^{1} \mathrm{H}-\mathrm{ROESY}-\mathrm{NMR}$ spectrum $(700 \mathrm{MHz})$ of PDP A1 in [D 6 DMSO. 


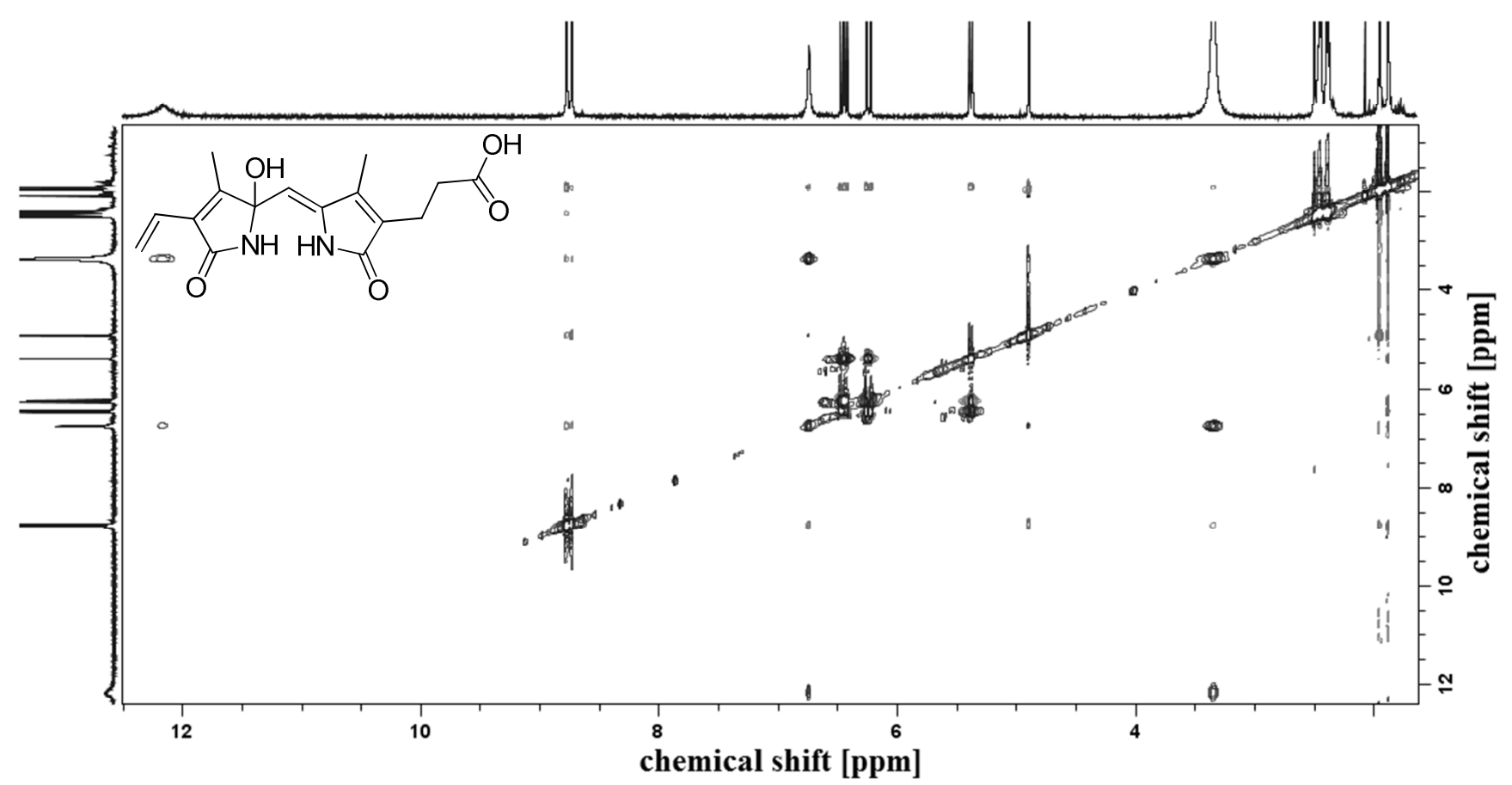

Figure S20: ${ }^{1} \mathrm{H},{ }^{1} \mathrm{H}-\mathrm{ROESY}-\mathrm{NMR}$ spectrum $(700 \mathrm{MHz})$ of PDP B1 in $\left[\mathrm{D}_{6}\right] \mathrm{DMSO}$.

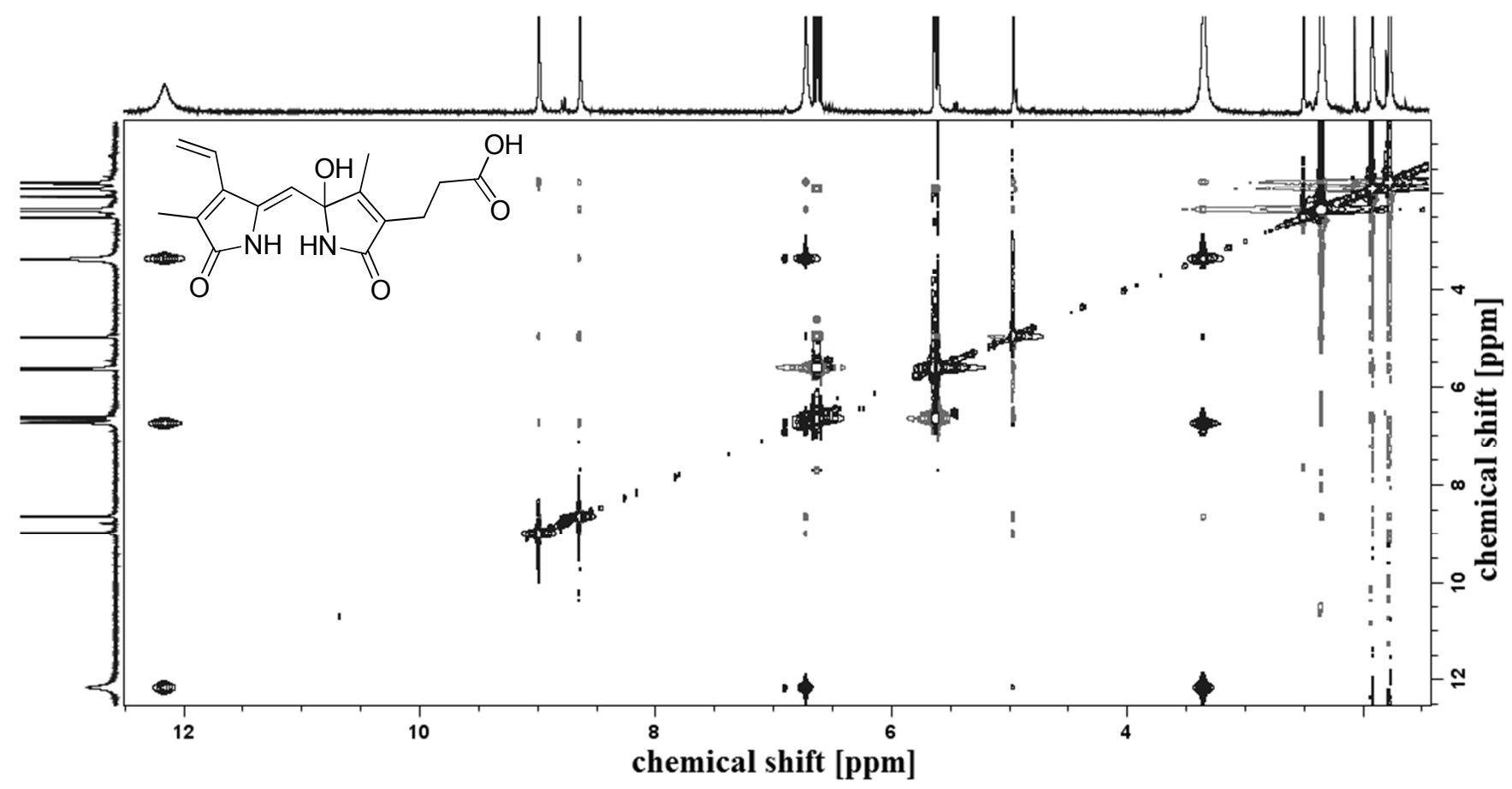

Figure S21: ${ }^{1} \mathrm{H},{ }_{1}^{1} \mathrm{H}-\mathrm{ROESY}-\mathrm{NMR}$ spectrum $(700 \mathrm{MHz})$ of PDP A2 in $\left[\mathrm{D}_{6}\right] \mathrm{DMSO}$. 


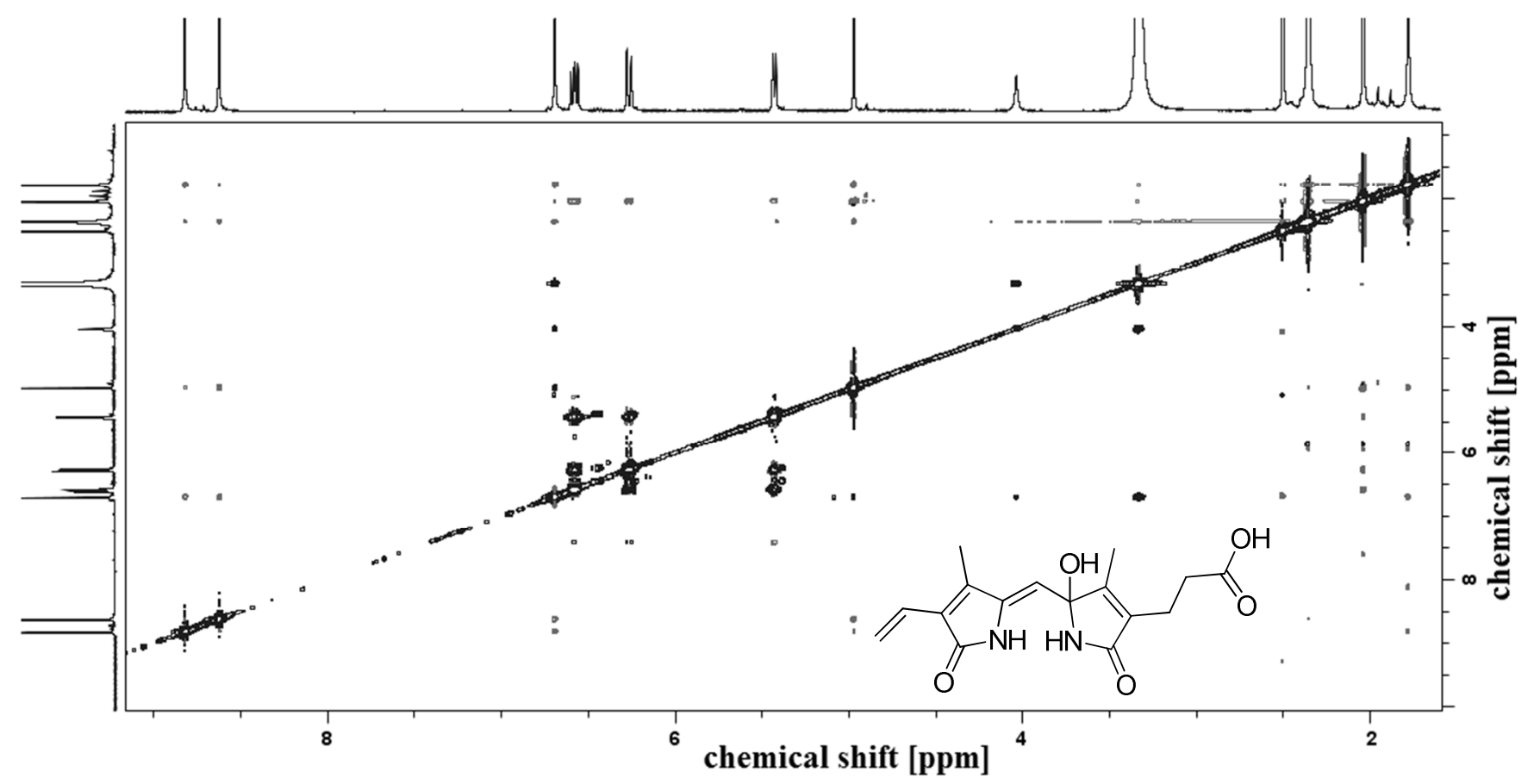

Figure S22: ${ }^{1} \mathrm{H},{ }^{1} \mathrm{H}-\mathrm{ROESY}-\mathrm{NMR}$ spectrum $(700 \mathrm{MHz})$ of PDP B2 in $\left[\mathrm{D}_{6}\right] \mathrm{DMSO}$.

$\underline{\text { IR spectra }}$

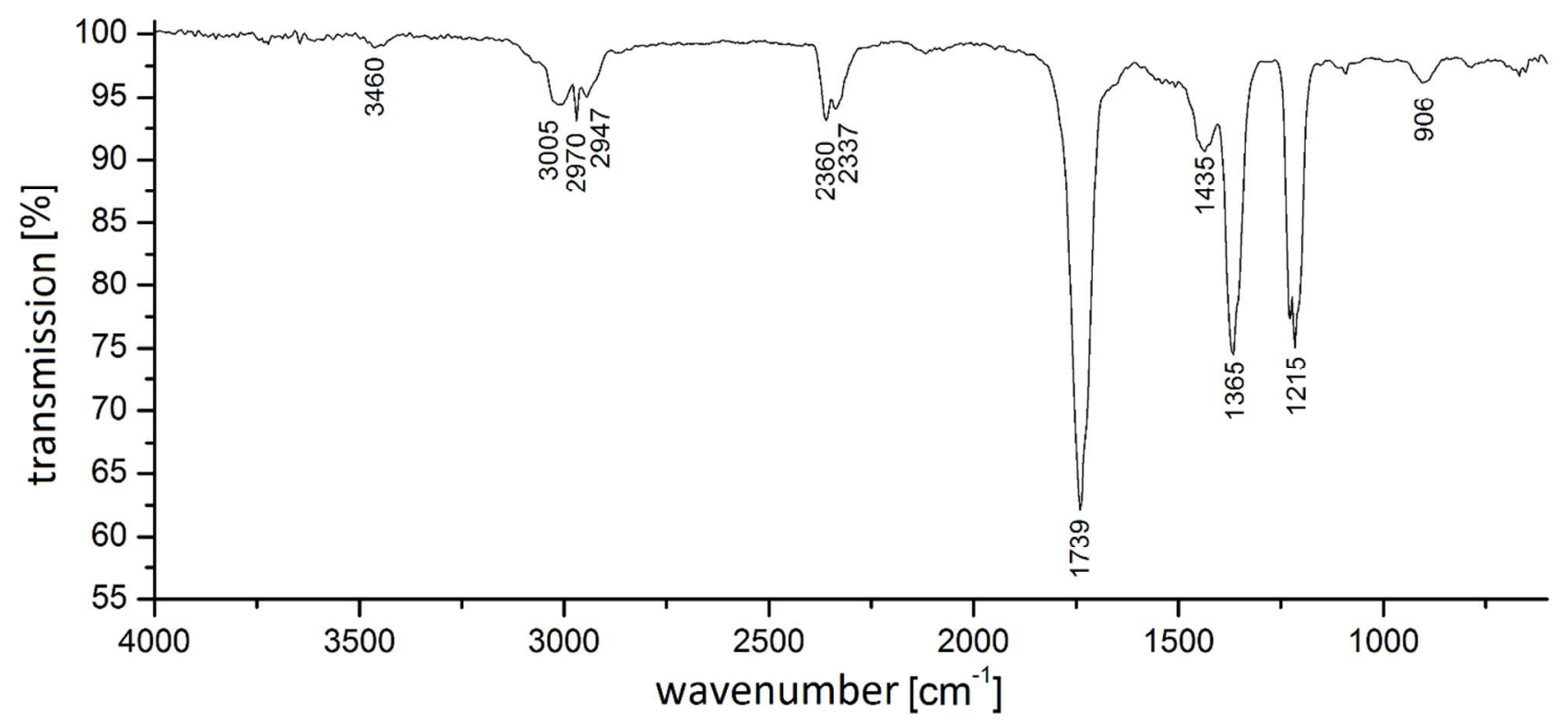

Figure S23: ATR-IR spectrum of PDP A1. 


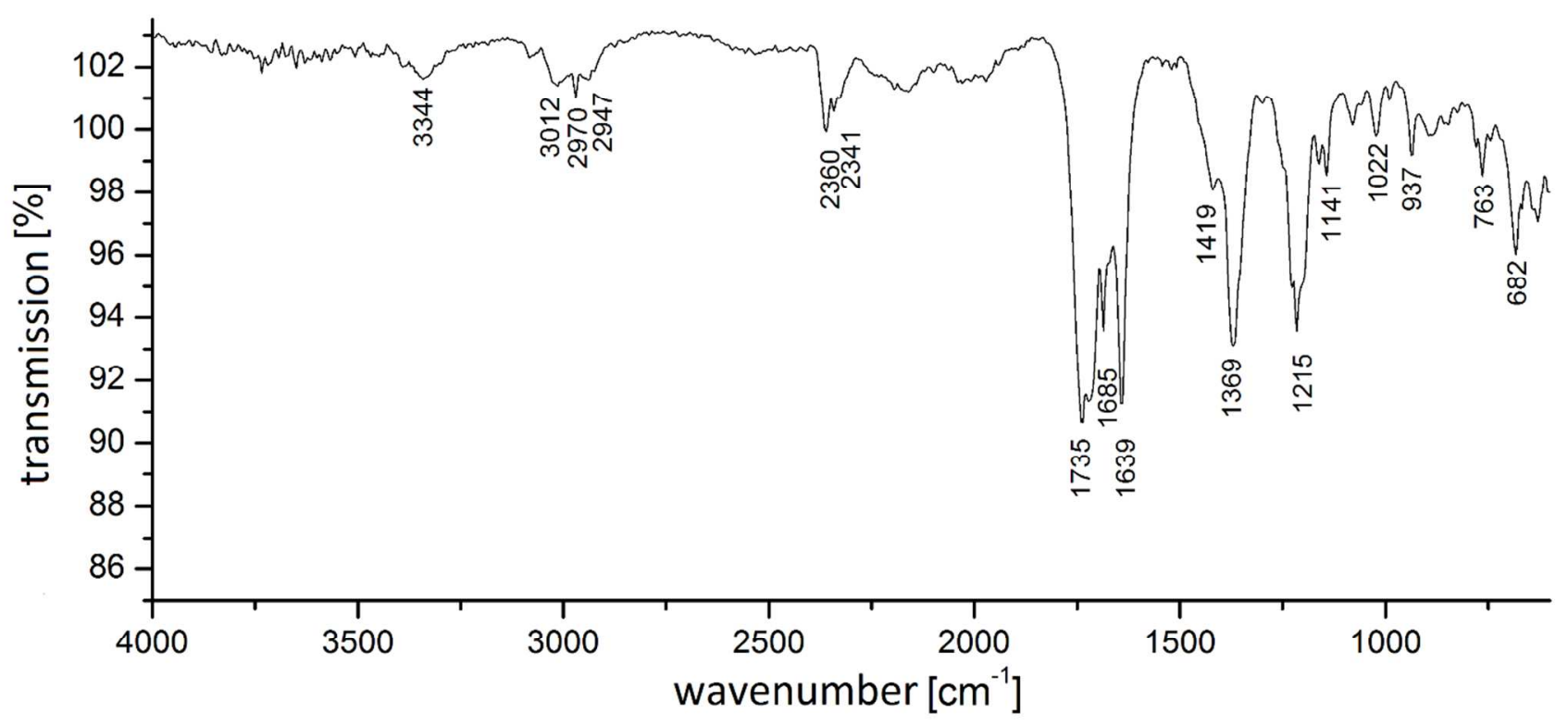

Figure S24: ATR-IR spectrum of PDP B1.

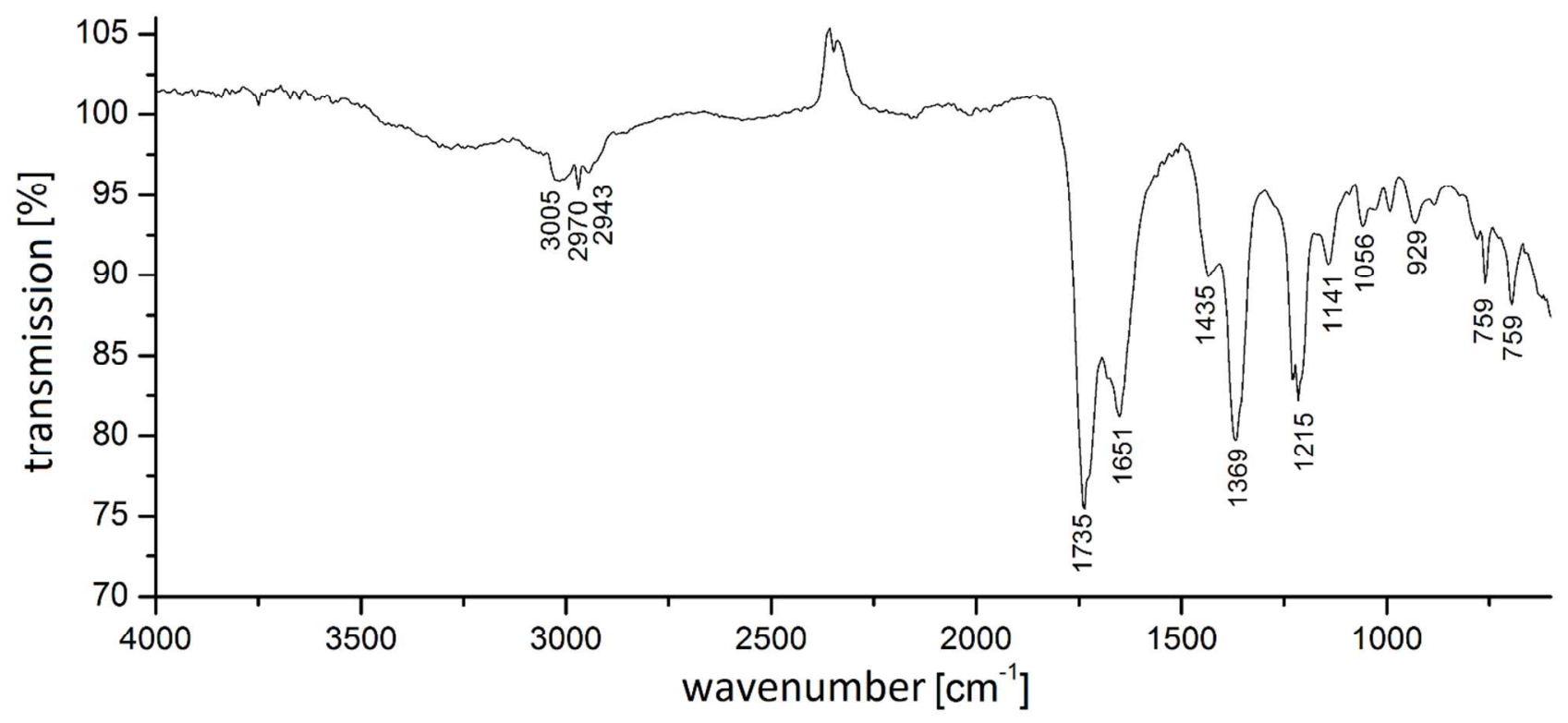

Figure S25: ATR-IR spectrum of PDP A2. 


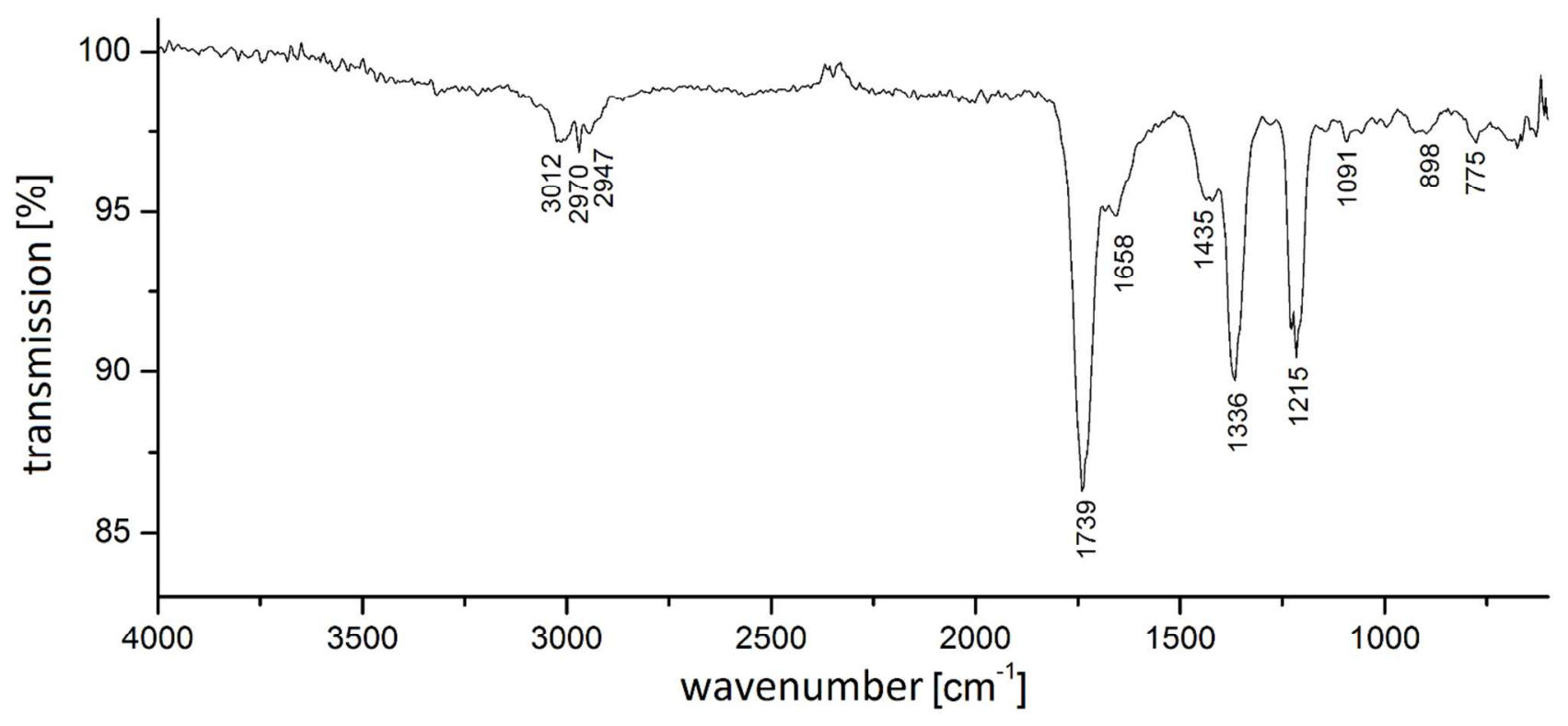

Figure S26: ATR-IR spectrum of PDP B2.

$\underline{\text { UV plots }}$

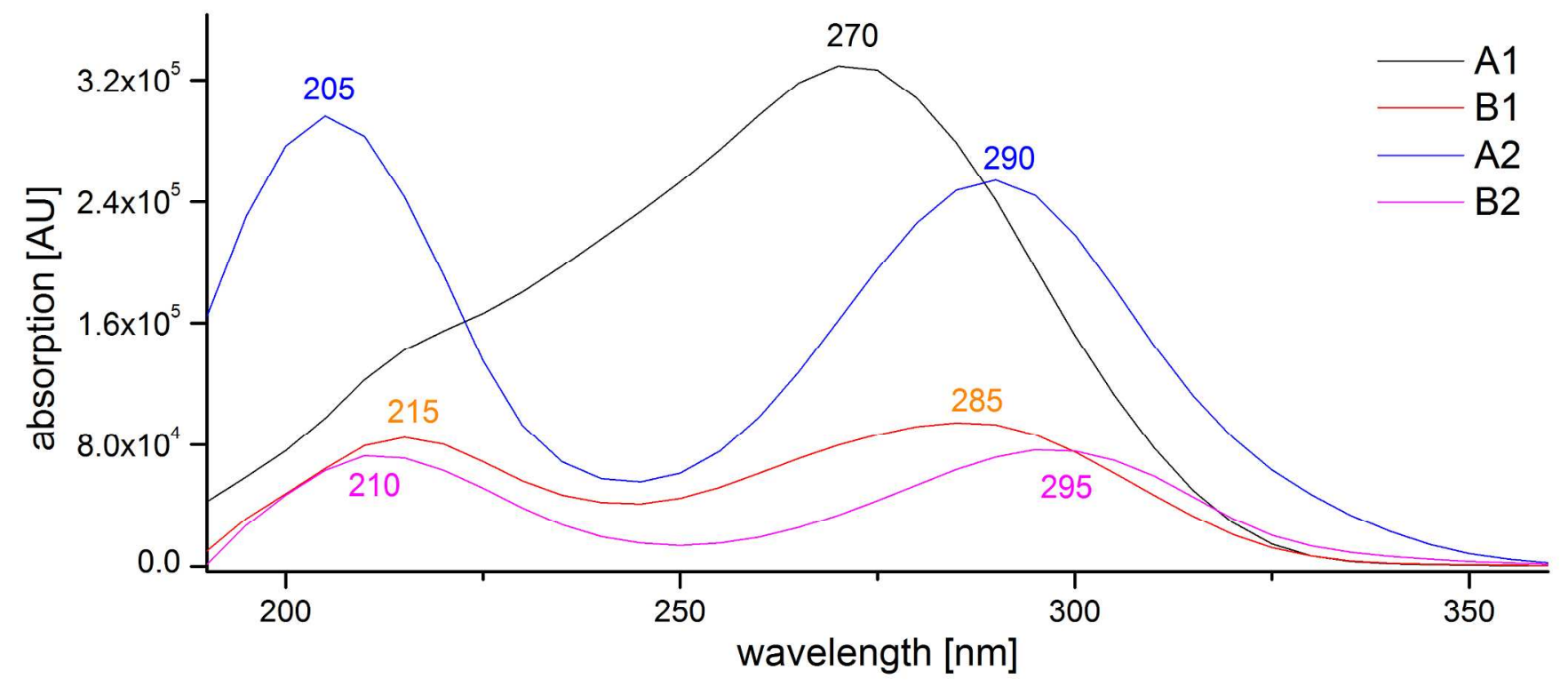

Figure S27: UV plots of PDP A1/2 and B1/2. 


\section{X-ray diffraction measurements}

The intensity data were collected on a Nonius KappaCCD diffractometer, using graphite-monochromated Mo- $\mathrm{K}_{\alpha}$ radiation. Data were corrected for Lorentz and polarization effects; absorption was taken into account on a semi-empirical basis using multiple-scans. ${ }^{[4-6]}$

The structure was solved by direct methods (SHELXS ${ }^{[7]}$ ) and refined by full-matrix least squares techniques against $\mathrm{Fo}^{2}$ (SHELXL-97 ${ }^{[7]}$ ). All hydrogen atom positions were included at calculated positions with fixed thermal parameters. The crystals of PDP A1 were extremely thin and of low quality, resulting in a substandard data set; however, the structure is sufficient to show connectivity and geometry despite the high final $R$ value. We therefore only report the structure as conformation of the suggested structure, but not as crystallographic data deposited the data in the Cambridge Crystallographic Data Centre.

MERCURY was used for structure representations ${ }^{[8]}$.

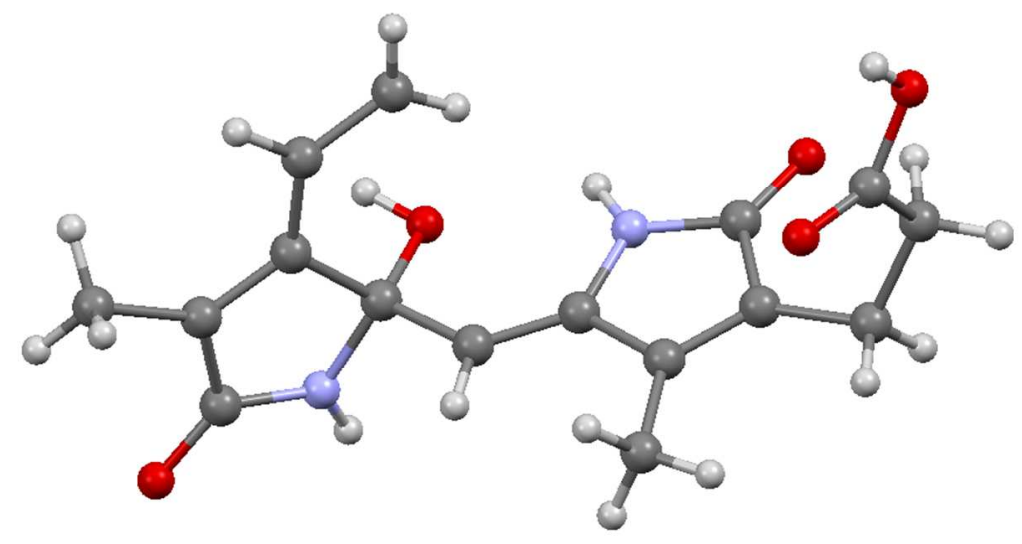

Figure S28: Motive of the structure of PDP A1 via X-ray diffraction.

Crystal Data for PDP A1 : $\mathrm{C}_{16} \mathrm{H}_{18} \mathrm{~N}_{2} \mathrm{O}_{5}, \mathrm{Mr}=318.32$ gmol $^{-1}$, colourless prism, size 0.124 x $0.068 \times 0.055 \mathrm{~mm}^{3}$, monoclinic, space group P $21 / \mathrm{n}, \mathrm{a}=12.2016(9), \mathrm{b}=7.6651(6), \mathrm{c}=16.3094(13) \AA, \beta=101.125(5)^{\circ}, \mathrm{V}=$ 1496.7(2) $\AA^{3}, \mathrm{~T}=-140{ }^{\circ} \mathrm{C}, \mathrm{Z}=4, \rho_{\text {calcd. }}=1.413 \mathrm{gcm}^{-3}, \mu\left(\mathrm{Mo}-\mathrm{K}_{\alpha}\right)=1.06 \mathrm{~cm}^{-1}$, multi-scan, transmin: 0.6387 , transmax: $0.7456, \mathrm{~F}(000)=672,13199$ reflections in $\mathrm{h}(-15 / 15), \mathrm{k}(-7 / 9), 1(-21 / 20)$, measured in the range $2.31^{\circ} \leq \Theta \leq 27.48^{\circ}$, completeness $\Theta_{\max }=98.9 \%, 3392$ independent reflections, largest difference peak and hole: $0.363 /-0.374$ e $\AA^{-3}$. 


\section{Standard addition}

To proof that the obtained crystal is PDP A1 it was diluted in water and solution, a control of all four PDPs and a standard addition of both was measured via LC-MS.

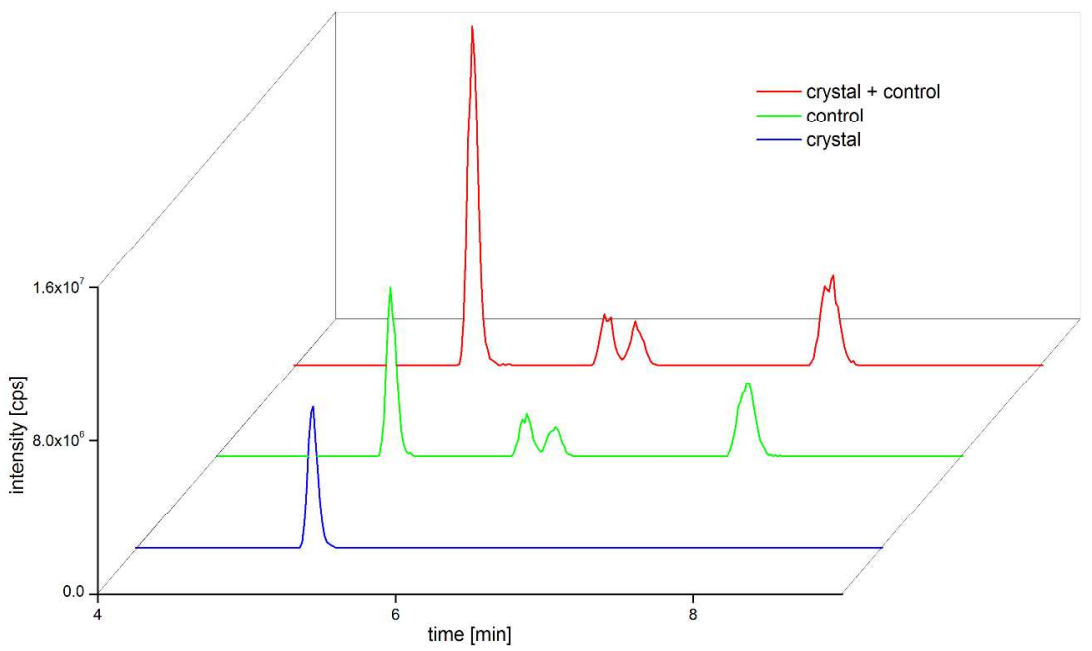

Figure S29: UHPLC-MS trace of solutions of the crystal, a control with all four PDPs and a combination of both to proof that the crystal was PDP A1.

\section{References}

(1) Seidel, R. A. et al. submitted 2016

(2) Seidel, R. A.; Kahnes, M.; Bauer, M.; Pohnert, G. J. Chromatogr. B 2015, 974, 83-89.

(3) Kranc, K. R.; Pyne, G. J.; Tao, L.; Claridge, T. D.; Harris, D. A.; Cadoux-Hudson, T. A.; Turnbull, J. J.; Schofield, C. J.; Clark, J. F. Eur. J. Biochem. 2000, 267 (24), 7094-7101.

(4) COLLECT, Data Collection Software; Nonius B.V., Netherlands, 1998

(5) Z. Otwinowski \& W. Minor, „Processing of X-Ray Diffraction Data Collected in Oscillation Mode“, in Methods in Enzymology, Vol. 276, Macromolecular Crystallography, Part A, edited by C.W. Carter \& R.M. Sweet, pp. 307-326, Academic Press, San Diego, USA, 1997

(6) SADABS 2.10, Bruker-AXS inc., 2002, Madison, WI, U.S.A

(7) Sheldrick, G. M. Acta Cryst. 2008. A46, 112-122.

(8) MERCURY, Macrae CF, Edgington PR, McCabe P, Pidcock E, Shields GP, Taylor R, Towler M, van de Streek J J Appl Cryst $200639: 453$ 